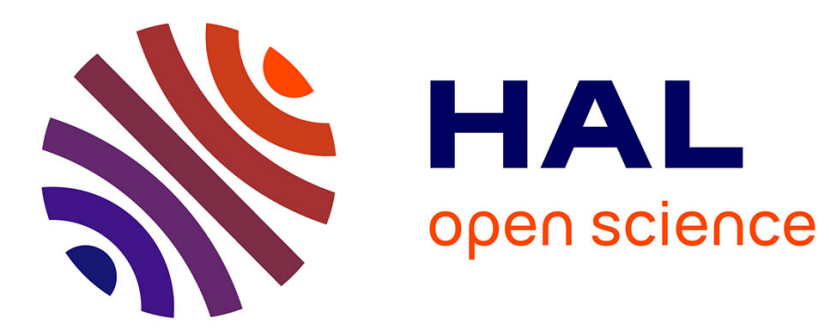

\title{
Teupolioside, a phenylpropanoid glycosides of , biotechnologically produced by IRBN22 plant cell line, exerts beneficial effects on a rodent model of colitis
}

Rosanna Di Paola, Emanuela Esposito, Emanuela Mazzon, Luisa Riccardi, Rocco Caminiti, Roberto Dal Toso, Giovanna Pressi, Salvatore Cuzzocrea

\section{To cite this version:}

Rosanna Di Paola, Emanuela Esposito, Emanuela Mazzon, Luisa Riccardi, Rocco Caminiti, et al.. Teupolioside, a phenylpropanoid glycosides of , biotechnologically produced by IRBN22 plant cell line, exerts beneficial effects on a rodent model of colitis. Biochemical Pharmacology, 2009, 77 (5), pp.845. 10.1016/j.bcp.2008.11.010 . hal-00531841

\section{HAL Id: hal-00531841 https://hal.science/hal-00531841}

Submitted on 4 Nov 2010

HAL is a multi-disciplinary open access archive for the deposit and dissemination of scientific research documents, whether they are published or not. The documents may come from teaching and research institutions in France or abroad, or from public or private research centers.
L'archive ouverte pluridisciplinaire HAL, est destinée au dépôt et à la diffusion de documents scientifiques de niveau recherche, publiés ou non, émanant des établissements d'enseignement et de recherche français ou étrangers, des laboratoires publics ou privés. 


\section{Accepted Manuscript}

Title: Teupolioside, a phenylpropanoid glycosides of Ajuga reptans, biotechnologically produced by IRBN22 plant cell line, exerts beneficial effects on a rodent model of colitis

Authors: Rosanna Di Paola, Emanuela Esposito, Emanuela Mazzon, Luisa Riccardi, Rocco Caminiti, Roberto Dal Toso,

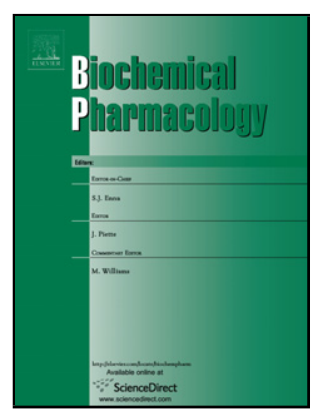

Giovanna Pressi, Salvatore Cuzzocrea

PII:

S0006-2952(08)00792-2

DOI: doi:10.1016/j.bcp.2008.11.010

Reference: BCP 10007

To appear in: $\quad B C P$

Received date: 2-10-2008

Revised date: $\quad 30-10-2008$

Accepted date: $\quad$ 5-11-2008

Please cite this article as: Di Paola R, Esposito E, Mazzon E, Riccardi L, Caminiti R, Dal Toso R, Pressi G, Cuzzocrea S, Teupolioside, a phenylpropanoid glycosides of Ajuga reptans, biotechnologically produced by IRBN22 plant cell line, exerts beneficial effects on a rodent model of colitis, Biochemical Pharmacology (2008), doi:10.1016/j.bcp.2008.11.010

This is a PDF file of an unedited manuscript that has been accepted for publication. As a service to our customers we are providing this early version of the manuscript. The manuscript will undergo copyediting, typesetting, and review of the resulting proof before it is published in its final form. Please note that during the production process errors may be discovered which could affect the content, and all legal disclaimers that apply to the journal pertain. 


\title{
Teupolioside, a phenylpropanoid glycosides of Ajuga reptans,
}

biotechnologically produced by IRBN22 plant cell line, exerts beneficial

\section{effects on a rodent model of colitis}

\author{
ROSANNA DI PAOLA ${ }^{1 *}$, EMANUELA ESPOSITO ${ }^{1,2,}$, EMANUELA MAZZON ${ }^{1}$, LUISA \\ RICCARDI $^{3}$, ROCCO CAMINITI ${ }^{4}$, ROBERTO DAL TOSO ${ }^{5}$, GIOVANNA PRESSI ${ }^{5}$ \& \\ SALVATORE CUZZOCREA, ${ }^{1,6}$.
}

*These authors contributed equally to the present results and share the first authorship.

${ }^{1}$ IRCCS Centro Neurolesi "Bonino-Pulejo", Messina, Italy; ${ }^{2}$ Department of Experimental Pharmacology, University of Naples "Federico II", Napoli, Italy; ${ }^{3}$ Department of Clinical and Experimental Medicine, University of Perugia, Italy; ${ }^{4}$ Department of Human Pathology, School of Medicine, University of Messina, Italy; ${ }^{5}$ I.R.B. srl Altavilla Vicentina Italy; ${ }^{6}$ Department of Clinical and Experimental Medicine and Pharmacology, School of Medicine, University of Messina, Italy.

\footnotetext{
Author for correspondence: Salvatore Cuzzocrea, Department of Clinical and Experimental Medicine and Pharmacology, School of Medicine, University of Messina, Torre Biologica, Policlinico Universitario Via C. Valeria, Gazzi, 98100 Messina Italy. Tel. (39) 090 2213644; Fax. (39) 090 2213300; email: salvator@unime.it
} 


\begin{abstract}
The aim of the present study was to examine the effects of phenylpropanoid glycoside, Teupolioside, biotechnologically produced by IRBN22 Ajuga reptans cell line, in rats subjected to experimental colitis.

Colitis was induced in rats by intracolonic instillation of dinitrobenzene sulfonic acid (DNBS). Teupolioside was administered daily orally (0.2 or $2 \mathrm{mg} \mathrm{kg-1).} \mathrm{On} \mathrm{Day} \mathrm{4,} \mathrm{animals} \mathrm{were}$ sacrificed and tissues were taken for histological and biochemical analysis.

Four days after DNBS administration, colon TNF- $\alpha$ and IL-1 $\beta$ productions were increased, associated with colon damage. Neutrophil infiltration, by myeloperoxidase activity, in the mucosa was associated with up-regulation of ICAM-1 and P-selectin and high levels of malondialdehyde. Immunohistochemistry for nitrotyrosine and poly (ADP-ribose) polymerase (PARP) showed an intense staining in the inflamed colon. Biochemical methods and zymography were used to analyze MMP-9 and -2 activities in colon tissues from DNBS-injured rats. Treatment with Teupolioside significantly reduced the appearance of diarrhoea and the loss of body weight. This was associated with a remarkable amelioration in the disruption of the colonic architecture and a significant reduction in colonic myeloperoxidase activity and malondialdehyde levels. Teupolioside also reduced the pro-inflammatory cytokines release, the appearance of nitrotyrosine and PARP immunoreactivity in the colon and reduced the up-regulation of ICAM-1 and the expression of P-selectin. Therefore, Teupolioside also reduced proMMP-9 and -2 activity induced in the colon by DNBS administration.
\end{abstract}

The results of this study suggested that administration of Teupolioside may be beneficial for treatment of inflammatory bowel disease. 


\section{Introduction}

Inflammatory bowel diseases (IBDs), such as Crohn's disease and ulcerative colitis, are chronic immune diseases of the gastrointestinal tract. Although the aetiologies of these diseases still remain unknown, the current hypothesis indicates that IBD results from an uncontrolled immune response to the normal gut flora [1]. Genetic factors and environmental factors both contribute to the damaging mucosal immune response [2]

The intestinal mucosa constitutes an immunologic system which plays a pivotal role in host defence. The mucosal immune system, is continuously exposed to large amounts of exogenous (i.e., dietary) and endogenous (e.g., bacterial) antigens [3]. Activation of lamina propia (LP) T cells by lumen antigens may lead to the production of inflammatory cytokines and subsequent mucosal inflammation and tissue damage[1,3,4]. In addition to immune factors as leukocytes, macrophages, polymorphonuclear cells, mast cells, B and T lymphocytes, other potential mediators of inflammation are involved in the disease: eicosanoids, biological amines, cytokines, nitrogen- and oxygen-reactive metabolites, platelet-activating factor have been noted to influence inflammatory processes [5]

It has been suggested that intestinal damage in IBD is related to increased free radical production and to impaired antioxidant defence systems [6]. There are an increased number of activated inflammatory cells in lamina propria of IBD releasing reactive oxygen radicals that are highly produced by neutrophils, macrophages and DCs [7], and exceeds the limited intestinal antioxidant defence system, contributing to intestinal oxidative injury in IBD[8].

The main goal of therapy for IBD is to induce a clinical remission and then maintain it for a long period of time, in order to realize the best attainable quality of life. Treatment with flavonoids can be efficient.

Flavonoids are polyphenolic compounds that occur ubiquitously in foods of plant origin and exert antimicrobial, antiviral, antineoplastic, antihepatotoxic, hypolipidemic, antiallergic and anti- 
inflammatory features [9]. Biochemical investigations of flavonoid mechanisms have demonstrated that these compounds inhibit a wide variety of enzymatic systems.

Phenylpropanoid glycosides (PPGs, also synonymous of phenylethanoid glycosides) are water soluble derivatives of phenylpropanoids (PPs), There is a growing evidence that PPGs, like other plant polyphenols in general and PPs in particular, are powerful antioxidants either by direct scavenging of reactive oxygen and nitrogen species, or by acting as chain-breaking peroxyl radical scavengers [10]. Recently, PPGs have been reported to possess multiple beneficial effects for human health. Indeed, they have been effective in the chemoprevention of tumors [11]; some have anti-inflammatory activity [12], while others have anti-thrombotic[13], wound healing [14], and cardio-protective actions [15]. These health effects of PPGs have been traditionally explained in terms of the prevention of free radicalassociated and transition metal-mediated cell and tissue damage.

Teupolioside (TP) belongs to the family of phenylpropanoids and is structurally characterized by caffeic acid (phenylpropanoid moiety) and 4,5 hydroxyphenylethanol (phenylethanoid moiety) bound to a $\beta$-[D]-glucopyranoside trough an ester and glycosidic links, respectively. Two other monocarbohydrates, rhamnose and galactose are linked in sequence to the glucose molecule (Figure 1). Very small amounts of teupolioside were initially isolated from Teucrium polium [11]

Structurally speaking, the phenylpropanoids are characterized by the presence of two catechol groups that are highly reactive in the presence of free radicals. In fact, experiments effected by Korkina L.G. et al [16], on the teupolioside molecule have demonstrated significant anti-inflammatory, anti-oxidant and chelating properties with bivalent metals, in particular for $\mathrm{Fe}^{2+}$.

The objectives of the present study was to address whether teupolioside exerted protection on the development of colonic inflammation induced by dinitrobenzene sulfonic acid (DNBS) in the rat. 


\section{MATERIALS AND METHODS}

\subsection{Reagents}

Biotin blocking kit, biotin-conjugated goat anti-rabbit IgG and avidin-biotin peroxidase complex were obtained from Vector Laboratories (Burlingame, CA, USA). All other reagents and compounds used were purchased from Sigma Chemical Company (Sigma, St. Louis, MO).

\subsection{Plant cell line}

The stabilized and highly selected cell line specified on the synthesis of teupolioside was obtained from dissected young Ajuga reptans leaves sterilized by $\mathrm{NaOCl}$ and Tween 20 . The stabilized and selected cell line was deposited at the Plant Cell Bank (DSMZ, Deutsche Sammlung Von Mikroorganismem un Zellkulturen, Braunschweig, Germany) coded internally IRBN22 and internationally DSM 16451. The IRBN22 plant cell line was used for the industrial culture fermentors.

\subsection{Teupolioside containing extract preparation}

Ajuga reptans IRBN22 cell cultures obtained at the end of the fermentation process were collected, homogenized, separeted by centrifugation, and the solid residue discarded. The yield of teupolioside was approx. $4 \mathrm{~g} / \mathrm{L}$ of the plant cell culture sospension. The teupolioside in the supernatant was recovered by solid phase extraction on XAD4 resin, followed by elution with 80/20 ethanol/water (V/V) mixture. Then, the eluted verbascoside was concentrated under reduce pressure and liophylized. The final extract, a pale yellow powder, contained teupolioside in an amount over $80 \%(\mathrm{w} / \mathrm{w}))$, together with minor admixture $(>10 \% \mathrm{w} / \mathrm{w})$ of other caffeic acid derivatives. The further purification of teupolioside was performed by repeated column chromatography on C18 silica gel and Sephadex LH20 and subsequent crystallization obtaining a final product with teupolioside content above $97 \%(\mathrm{w} / \mathrm{w})$. The standard raw extract with a purity of $50 \pm 1 \%(\mathrm{w} / \mathrm{w})$ was obtained from the $80 \%(\mathrm{w} / \mathrm{w})$ cell extract by addition of maltodextrins. 


\subsection{HPLC analysis}

The analysis was performed using HPLC system (Agilent, series 1100 DAD, HewlettPackard) consisting of an auto sampler, high pressure mixing pump, and the column C18 (2) Phenomenex 4.6 X $150 \mathrm{~mm}$. The gradient system was : Phase A - water/0.01N phosphoric acid; Phase B: acetonitryl/ $0.01 \mathrm{~N}$ phosphoric acid. Flow rate was $1 \mathrm{~mL} / \mathrm{min}$. DAD: UV maximum absorbance at $330 \mathrm{~nm}$.

\subsection{Animals}

Male Sprague-Dawley rats (300-350 g, Charles River, Milan, Italy) were placed single in cages with wire-net floors in a room with controlled environment, (temperature $24-25^{\circ} \mathrm{C}$, humidity $70-75 \%$, lighting regimen of $12 \mathrm{~L} / 12 \mathrm{D}$ ) and provided with standard rodent chow and water. Animal care was in compliance with Italian regulations on protection of animals used for experimental and other scientific purpose (D.M. 116192) as well as with the EEC regulations (O.J. of E.C. L 358/1 12/18/1986). Experiments followed a protocol approved by the local animal Ethics Committee and the Local Government.

\subsection{Experimental Group}

Animals were randomly divided into 6 groups $(\mathrm{n}=10$ for each group):

1. Sham + Vehicle group: Vehicle solution (saline) was administered daily orally.

2. Sham + Teupolioside $(0.2 \mathrm{mg} / \mathrm{kg})$ : TP $(0.2 \mathrm{mg} / \mathrm{kg})$ was administered daily orally.

3. Sham + Teupolioside $(2 \mathrm{mg} / \mathrm{kg})$ : TP $(2 \mathrm{mg} / \mathrm{kg})$ was administered daily orally.

4. DNBS + Vehicle: Vehicle was administered daily orally and animals were sacrificed on day 4 after administration of DNBS.

5. DNBS + TP $(2 \mathrm{mg} / \mathrm{kg})$ : TP was administered as by gavage at $2 \mathrm{mg} / \mathrm{kg}$ every $24 \mathrm{~h}$, starting from 3 hour after the administration of DNBS. 
6. DNBS $+\mathrm{TP}(0.2 \mathrm{mg} / \mathrm{kg}) \mathrm{TP}$ was administered as by gavage at $0.2 \mathrm{mg} / \mathrm{kg}$ every $24 \mathrm{~h}$, starting from 3 hour after the administration of DNBS.

The dose of TP $(0,2$ and $2 \mathrm{mg} / \mathrm{kg})$ used here were based on previous dose-response and time-course studies by our laboratory.

\subsection{Induction of experimental colitis}

Colitis was induced by using a technique of acid-induced colonic damage as described previously . Briefly, in fasted rats lightly anaesthetized with isoflurane, a $3.5 \mathrm{~F}$ catheter was inserted into the colon via the anus until approximately the splenic flexure $(8 \mathrm{~cm}$ from the anus). 2,4,6-dinitrobenzene sulfonic acid (DNBS; $25 \mathrm{mg} / \mathrm{rat}$ ) was dissolved in $50 \%$ ethanol (total volume, $0.8 \mathrm{ml}$ ) and deposited into the colon. Thereafter, the animals were kept for $15 \mathrm{~min}$ in a Trendelenburg position to avoid reflux. After colitis and sham colitis (animals treated with $0.8 \mathrm{ml}$ of $50 \%$ ethanol) induction, the animals were observed for 3 days. On Day 4 , the animals were weighed and anaesthetized with chloralium hydrate ( $400 \mathrm{mg} / \mathrm{kg}$, intraperitoneally), and the abdomen was opened by a midline incision. The entire colon was removed, isolated from surrounding tissues, opened along the antimesenteric border, rinsed, weighed, and processed for histology and immunohistochemistry.

\subsection{Evaluation of colon damage}

After its removal, the entire colon was gently rinsed with saline solution, opened by a longitudinal incision, and immediately examined under a microscope. Colon damage (macroscopic damage score) was evaluated and scored by two independent observers as described previously according to the following criteria: 0 , no damage; 1 , localized hyperemia without ulcers; 2 , linear ulcers with no significant inflammation; 3 , linear ulcers with inflammation at one site; 4 , two or more major sites of inflammation and ulceration extending $>1 \mathrm{~cm}$ along the length of the colon; and 5-8, one point is added for each centimeter of ulceration beyond an initial $2 \mathrm{~cm}$. 


\subsection{Optical microscopy}

After fixation for 1 week at room temperature in Dietrich solution $(14.25 \%$ ethanol, $1.85 \%$ formaldehyde, $1 \%$ acetic acid), entire colon samples were dehydrated in graded ethanol and embedded in Paraplast (Sherwood Medical, Mahwah, New Jersey). Thereafter, 7- $\mu \mathrm{m}$ sections were deparaffinized with xylene, stained with haematoxylin-eosin and observed in a Dialux 22 Leitz (Wetzlar, Germany) microscope. In order to have a quantification (quantitative estimation) of colon damage, each section ( $\mathrm{n}=6$ for each animals) was scored by 2 independent observers blinded to the experimental protocol. The following morphological criteria were considered: score 0, no damage; score 1 (mild), focal epithelial edema and necrosis; score 2 (moderate), diffuse swelling and necrosis of the villi; score 3 (severe), necrosis with presence of neutrophil infiltrate in the submucosa; score 4 (highly severe), widespread necrosis with massive neutrophil infiltrate and hemorrhage.

\subsection{Measurement of cytokines}

TNF- $\alpha$ and IL- $1 \beta$ levels were evaluated in the entire colon tissues collected at 4 days after DNBS administration. The assay was carried out by using a colorimetric, commercial kit (Calbiochem-Novabiochem Corporation, USA) according to the manufacturer instructions.

\subsection{Myeloperoxidase activity}

Myeloperoxidase (MPO) activity, an indicator of polymorphonuclear leukocyte accumulation, was determined as published previously [17]. 


\subsection{Thiobarbituric acid-reactant substances measurement}

As a marker of lipid peroxidation, thiobarbituric acid-reactant substances measurement was performed (determined), as previously described in the colon tissue at 4 days after DNBS administration. Thiobarbituric acid-reactant substances were calculated by comparison with $\mathrm{OD}_{650}$ of standard solutions of 1,1,3,3-tetramethoxypropan 99\% malondialdehyde bis (dymethyl acetal) 99\% (MDA) (Sigma, Milan). The absorbance of the supernatant was measured by spectrophotometry at $650 \mathrm{~nm}$.

\subsection{Immunohistochemical localisation of ICAM-1, P-Selectin, iNOS, nitrotyrosine, PAR,} TNF- $\alpha$ and IL-1 $\beta$.

Immunohistochemical localisation of ICAM-1, P-Selectin, iNOS, nitrotyrosine, PAR, TNF$\alpha$ and IL-1 $\tilde{\beta}$ was determined as published previously (18)

\subsection{Western blot analysis for IкB- $\alpha$, phospho-NF-кB p65 (serine 536), NF-кB p65, MMP-2 and MMP-9}

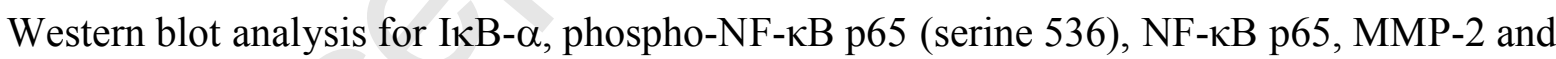
MMP 9 was determined as published previously (18)

\subsection{Gelatin zymography}

The activity of gelatinases (A or matrix metalloproteinase type 2 MMP-2, and B or MMP9) activity was measured as previously described in colonic homogenates. Briefly, colonic samples were homogenized, mixed with electrophoresis loading buffer and subjected to $10 \%$ sodium dodecyl sulfate-polyacrylamide gel electrophoresis (SDS-PAGE) with copolymerized gelatin (0.2\%; Sigma Chemical Co, St. Louis, Mo). After electrophoresis, the gels were washed 
and gently shaken in three consecutive washings in $2.5 \%$ Triton X-100 solution to remove SDS. The gel slabs were then incubated at $37^{\circ} \mathrm{C}$ overnight in development buffer $(50 \mathrm{mmol} / \mathrm{L}$ Tris $\mathrm{HCl}$, $200 \mathrm{mmol} / \mathrm{L} \mathrm{NaCl}, 10 \mathrm{mmol} / \mathrm{L} \mathrm{CaCl} 2$ and $1 \mu \mathrm{mol} / \mathrm{L} \mathrm{ZnCl} 2, \mathrm{pH}=7.5)$ and subsequently stained with $0.5 \%$ Coomassie Blue. After intensive destaining (4\% methanol with $8 \%$ acetic acid), proteolysis areas appeared as clear bands against a blue background. Molecular weight markers were used as standards. To measure the activities of the detected enzymes, zymograms were read using a ScanJet scanner. The intensities of the separate bands were analyzed using Gel measurement software. Quantitative evaluation of both surface and intensity of lysis bands, on the basis of grey levels, were compared relative to non-treated control wells and expressed as 'relative expression' of gelatinolytic activity.

\subsection{Data analysis}

All values in the figures and text are expressed as mean \pm standard error (s.e.m.) of the mean of $n$ observations. For the in vivo studies $n$ represents the number of animals studied. In the experiments involving histology or immunohistochemistry, the figures shown are representative of at least three experiments performed on different experimental days. The results were analyzed by one-way ANOVA followed by a Bonferroni post-hoc test for multiple comparisons. A $p$-value less than 0.05 was considered significant. 


\section{RESULTS}

\section{Effects of TP treatment on the degree of colitis}

No histological alteration was observed in the colon tissue from sham-treated rats (Figure 2a see macroscopic score $2 \mathrm{~h}$; $2 \mathrm{c}$ see histological score $2 \mathbf{i}$ ). Four days after intra-colonic administration of DNBS, the colon appeared flaccid and filled with liquid stool. The macroscopic inspection of cecum, colon and rectum showed presence of mucosal congestion, erosion and hemorrhagic ulcerations (Figure 2b see macroscopic score 2h). The histopathological features included a transmural necrosis and edema and a diffuse leukocyte cellular infiltrate in the submucosa of colon section from DNBS-treated rats (Figure $2 \mathbf{f}$ see histological score $2 \mathbf{i}$ ). The treatment with TP significantly reduced in a dose dependent manner the extent and severity of the macroscopic (Figure 2c,d respectively, see macroscopic score $2 \mathbf{h}$ ) and histological signs of colon injury (Figure $2 \mathrm{~g}$ respectively see histological score $2 \mathbf{i}$ ). Four days after colitis induced by DNBS treatment, all rats had diarrhea and a significant reduction in body weight (compared with the sham groups of rats) (Figure 2l). TP treatment resulted in a significant reduction of lost of body weight induced by DNBS-administration in rats (Figure 21).

\section{TP reduced production and expression of TNF- $\alpha$ and IL-1 $\beta$ after DNBS administration.}

To test whether TP treatment modulates the inflammatory process through the regulation of the secretion of cytokines, we analyzed the colon levels of pro-inflammatory cytokines TNF$\alpha$ and IL-1 $\beta$. A substantial increase of TNF- $\alpha$ (Figure 3g) and IL-1 $\beta$ (Figure 3h) formation was found in the colon tissues collected at 4 days after DNBS administration. Colon levels of TNF- $\alpha$ ( Figure 3g) and IL-1 $\beta$ (Figure 3h) were significantly reduced in DNBS-treated rats which have received TP. Positive staining for TNF- $\alpha$ (Figure 3g see densitometry analysis 3c) and for IL-1 $\beta$ (Figure 3d see densitometry analysis 3f) was mainly localized in the infiltrated inflammatory cells in damaged tissues. The treatment with TP $2 \mathrm{mg} / \mathrm{kg}$ reduced the staining for TNF- $\alpha$ (Figure 
3b see densitometry analysis $3 \mathbf{c}$ ) and for IL-1 $\beta$ (Figure 3csee densitometry analysis $3 f$ ) in the colon tissues collected from DNBS-treated rats.

\section{Effects of TP treatment on ICAM-1 and P-selectin expression and neutrophils infiltration.}

The colitis caused by DNBS was also characterized by an increase in myeloperoxidase activity, an indicator of the neutrophils accumulation in the colon (Figure $\mathbf{4 g}$ ). This finding is consistent with the observation made with light microscopy that the colon of vehicle-treated DBNS-rats contained a large number of neutrophils. On the contrary, TP treatment significantly reduced the degree of PMN infiltration (determined as increase in MPO activity) in inflamed colon (Figure 4g).

To further elucidate the effect of TP treatment on neutrophils accumulation in inflamed colon, we evaluated the intestinal expression of ICAM-1 and P-selectin. Positive staining for ICAM-1 (Figure 4a see densitometry analysis 4c) and for P-selectin (Figure 4d see densitometry analysis $4 \mathbf{f}$ ) was substantially increased in the vessels of the lamina propria and submucosa as well as in epithelial cells of injured colon and in infiltrated inflammatory cells in damaged tissues from DNBS-treated rats. The treatment with TP at $2 \mathrm{mg} / \mathrm{kg}$ reduced the staining for ICAM-I (Figure 4b see densitometry analysis 4c) and for P-selectin (Figure 4e see densitometry analysis 4f) in the colon tissues collected from DNBS-treated rats.

\section{Effects of TP treatment on iNOS expression}

Positive staining for iNOS (Figure 5b see densitometry analysis 5d) was substantially increased in the epithelial cells of injured colon and in infiltrated inflammatory cells in damaged tissues from DNBS-treated rats. The treatment with TP at $2 \mathrm{mg} / \mathrm{kg}$ reduced the staining for iNOS (Figure 5c see densitometry analysis $\mathbf{5 d}$ ) in the colon tissues collected from DNBS-treated rats. No positive staining for iNOS (Figure 5a) was observed in the colon tissues collected from shamtreated rats. 


\section{Effects of TP treatment on nitrotyrosine formation, lipid peroxidation, and PAR formation}

Four days after DNBS administration, nitrotyrosine, a specific marker of nitrosative stress, was measured by immunohistochemical analysis in the terminal colon sections to determine the localization of "peroxynitrite formation" and/or other nitrogen derivatives produced during experimental colitis. Colon sections obtained from DNBS-treated rats exhibited positive staining for nitrotyrosine (Figure 6a see densitometry analysis 6c). The positive staining was mainly localized in inflammatory cells as well as around the vessels. TP treatment $(2 \mathrm{mg} / \mathrm{kg})$ reduced the degree of positive staining for nitrotyrosine (Figure $\mathbf{6 b}$ see densitometry analysis $6 \mathbf{c}$ ) in the colon. In addition, at 4 days after DNBS administration, thiobarbituric acid-reactant substances levels were also measured in the colon tissues as an indicator of lipid peroxidation. A significant increase of thiobarbituric acid-reactant substances (Figure 6g) were observed in the colon tissues collected from DNBS-treated rats at 4 days after the induction of experimental colitis when compared with sham-treated rats. Thiobarbituric acid-reactant substances (Figure 6g) were significantly attenuated in a dose-dependent fashion by the TP treatment. In our study, immunohistochemistry for PAR, as an indicator of in vivo PARP activation, revealed the occurrence of positive staining for PAR localized in nuclei of inflammatory cells in the colon tissues from DNBS-treated rats (Figure 6d see densitometry analysis 6f). TP treatment (2 $\mathrm{mg} / \mathrm{kg}$ ) reduced the degree of positive staining for PAR (Figure 6e see densitometry analysis $6 \mathbf{f}$ ) in the colon.

\section{Effects of TP treatment on NF- $\mathrm{KB}$ activation in colon tissues}

Most inflammatory mediators, including ICAM-1, iNOS, TNF- $\alpha$ and IL-1 $\beta$ are controlled

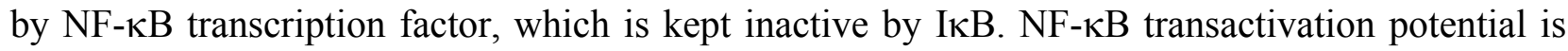
increased by phosphorylation of the p65 subunit. Since the levels of pro-inflammatory markers 
evaluated are lower in colon tissues from DNBS-treated rats which have received TP as compared to the vehicle treated animals we evaluated $\mathrm{I} \kappa \mathrm{B}$, phospho-p65 and NF- $\kappa \mathrm{B}$ p65 expression by Western Blot analysis. A basal level of IкB- $\alpha$ was detected in the colon tissues from sham-treated rats, whereas in DNBS-treated rats I $\kappa$ B- $\alpha$ levels were substantially reduced (Figure 7, panels a and a1). A significant reduced levels of $\mathrm{I} \kappa \mathrm{B}-\alpha$ degradation were observed in the colon lung tissues collected from TP $(2 \mathrm{mg} / \mathrm{kg})$ treated rats (Figure 7, panels a and a1).

Furthermore, DNBS administration caused a significant increase in the phosphorylation of p65 on Ser536 in the colon tissues from DNBS-treated rats and a significant reduction of p65 phosphorylation in the colon tissues from DNBS-treated rats which have received TP (Figure 7, panels $\mathbf{b}$ and b1). Moreover, NF- $\kappa \mathrm{B}$ p65 subunit presence in the nuclear fractions from colon tissue was also significantly increased after DNBS instillation compared to the sham-treated rats (Figure 7, panels c and c1). A significant reduction of the NF- $\kappa \mathrm{B}$ p65 nuclear levels was observed in the tissues from TP treated rats (Figure 7 panels $\mathbf{c}$ and $\mathbf{c 1 ) .}$

\section{Effects of TP treatment on matrix metalloproteinases expression in colon tissues}

To assess whether colon injury is associated with the alterations in activity and expression of secreted MMP-9 and -2, rats were sacrificed at 4 days after DNBS administration and colon were subjected to zymography and Western blot analysis, respectively, as described in Materials and Methods. A representative zymography and its densitometric analysis (Figure 8 panel a) shows both secreted MMP-9 and -2 activities. Pro-MMP-2 activity is observed in colonic extracts prepared from sham-treated rats (Figure 8 panel a, see densitometry analysis 8b). Administration of DNBS (Figure 8 panel a) significantly increased MMP-2 (both pro and active see densitometry analysis $\mathbf{8 b}, \mathbf{c}$ respectively) activity as compared with sham animals whereas pro and active MMP-9 activity

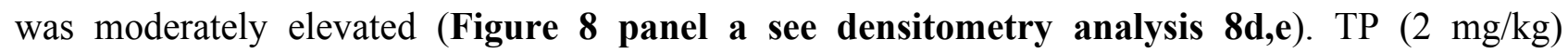


treatment attenuated the degree of activation of pro-MMP-2 and MMP-9 activity (Figure 8 panel a, see densitometry analysis $8 d-e$ ).

The low availability of active MMP-9 seen in the zymographies may be due to its high level of instability and the removal of active enzyme during the washing of specimens, as it has been previously suggested .

Western blot analysis of colonic homogenates showed a basal levels of total MMP-2 from control rats, as shown by the immunoreactive band migrating at $\sim 72 \mathrm{kDa}$ (Figure 9 panel a see densitometry analysis 9a1). A significant upregulation of MMP-2 expression was observed in the colon tissues from rats treated with DNBS when compared with controls. TP $(2 \mathrm{mg} / \mathrm{kg})$ treatment significantly prevented DNBS-induced MMP-2 expression (Figure 9 panel a see densitometry analysis 9a1). Similarly, a basal level of total MMP-9 was detected in tissues from control rats, as shown by the immunoreactive band migrating at $\sim 95 \mathrm{kDa}$ (Figure 9 panel b see densitometry analysis 9b1). A significant upregulation of MMP-9 expression was observed in the colon tissues from rats treated with DNBS when compared with controls. TP $(2 \mathrm{mg} / \mathrm{kg})$ treatment also significantly prevented DNBS-induced MMP-9 expression (Figure 9 panel b see densitometry analysis 9b1). 


\section{DISCUSSION}

Crohn's disease (CD) and ulcerative colitis (UC), collectively referred as inflammatory bowel diseases (IBD), are relatively common diseases of the gastrointestinal tract. IBD are characterized by dysfunction of mucosal immune response, abnormal cytokine production with increase in tumor necrosis factor (TNF)- $\alpha$ and interleukin (IL)-1, augmentation in adhesion molecules expression and cell infiltrate that ultimately lead to epithelial cell apoptosis and mucosal damage [19-21]. Although the etiology of IBD remains unknown, there is circumstantial evidence supporting a central role for disregulation of mucosal $\mathrm{CD}^{+} \mathrm{T}$ helper-1 (Th1) effectors cell responses to the normal enteric bacterial flora as a common disease mechanism[22]

Several animal models of IBD have been developed. Between these, the hapten model of colonic inflammation induced by dinitrobenzene sulfonic acid (DNBS) delivered intrarectally to normal mice displays human CD-like features, notably predominant NF-kB-dependent Th1 activation [19].

Polyphenols are phytochemicals that are abundant in food and beverages derived from plants. Although no deficiency- state has been described for them, increased intake of polyphenols appears to protect against disease in virtue of their anti-inflammatory and vasculo-protective properties.

Shapiro and collegues demonstrated that polyphenols with established anti-inflammatory properties: resveratrol, epigallocatechin gallate, curcumin and quercetin, in rodents, inhibits Nuclear Factor Kappa B-dependent gene expression. Conditions prevented and/or ameliorated by these polyphenols include inflammatory colitis. [23]

The present findings demonstrate that TP from IRBN22 plant cell line attenuates DNBS-induced colitis in the rats. What, then, is the mechanism by which TP inhibit the colon inflammation caused by injection of DNBS?

The intestinal mucosa is vulnerable to oxidative stress from constant exposure to reactive oxygen species (ROS) generated by the lumen contents [7]. Oxidative stress can cause cell 
damage either directly or through altering signaling pathways. Oxidative stress is a unifying mechanism of injury in many types of disease processes, including gastrointestinal diseases..it has been demonstrated that Oxidant-mediated injury plays an important role in the pathophysiology of IBD [8].

At the histological level, in the present study we observed that epithelial disruption was significantly less in rats treated with TP. Indeed, Furthermore, TP-treated rats are more resistant to DNBS induced colitis with a significant resolution of the macroscopic and histological signs of the inflammatory process.

Reactive oxygen species, either directly or via the formation of lipid peroxidation products, may play a role in enhancing inflammation through the activation of stress kinases (c-Jun activated kinase, extracellular signal-regulated kinase, p38) and redox-sensitive transcription factors, such as nuclear factor (NF)-kappaB. This results in increased expression of a battery of distinct pro-inflammatory mediators.

We report here that DNBS caused a significant increase in the phosphorylation of NF- $\mathrm{kB}$ p65 on Ser536 in the colon tissues at 4 day, whereas treatment with TP significantly reduced this phosphorylation. Moreover, we also demonstrate that the TP inhibited IкB- $\alpha$ degradation. The exact mechanisms by which TP suppress NF-kB activation in inflammation are not completely known. However, there are various study which have clearly demonstrated that potent anti-oxidant prevent the NF-KB activation .

It has been demonstrated that, NF-kappaB regulates the expression of antiapoptotic genes, cyclooxygenases (COXs) and metalloproteinases (MMPs) as well, Matrix metalloproteinases-are considered to be an important component in the progression of inflammation.

The role of NF-kappaB in regulation of MMP-9 was demonstrated further by the inhibition of MMP-9 production by proteasome inhibitors, lactacystin and MG-132, which prevented the ubiquitination and dissociation of IkappaB from NF-kappaB.[24] 
There is also growing evidence that MMPs can be implicated in the pathophysiology of several intestinal inflammatory disorders. In fact, MMPs can be released from almost all connective tissue cells present in the bowel in response to inflammatory stimuli. including inflammatory bowel disease, necrotizing enterocolitis, collagenous colitis, and diverticulitis.[25]

Activation of nuclear factor (NF) kappaB and mitogen-activated protein kinase (MAPK) pathways has been shown to enhance the gene expression of several enzymes that play an important role in maintaining oxidant-antioxidant homeostasis, such as inducible nitric oxide synthase (iNOS).[26]

There is a large body of evidence that the inducible form of the NO synthase enzyme (iNOS) that is responsible for high-output production of NO from 1-arginine is up-regulated in various forms of mucosal inflammation. Consistent with this, multiple detection strategies have demonstrated that iNOS expression, enzymatic activity, and NO production are increased in human inflammatory bowel disease tissues. There is also evidence that the level of iNOS-derived NO correlates with the initiation and maintenance of inflammation in human inflammatory bowel disease (IBD).[27]

We demonstrate here that the induction of iNOS protein in macrophages and epithelial cells caused by injection of DNBS is reduced in the colon from TP-treated rats. This effect may be related to the demonstrated inhibitory effect of TP on the activation of the transcription factor nuclear kappa B

Reactive oxygen species or peroxynitrite, coming from the reaction of nitric oxide and superoxide anion, are strong oxidants capable of damaging lipids, proteins and DNA. Some of these oxidative products are markers of oxidative stress. For example malondialdehyde and isoprostanes are oxidative markers of lipids, However other products are also produced, as is the case of the reaction of peroxynitrite with tyrosine which leads to the formation of 3nitrotyrosine.[28]

We report here that DNBS caused a significant increase nitrotirosine in the colon tissues at 
4 day, whereas treatment with TP significantly reduced this expression.

Nitrotyrosine formation, along with its detection by immunostaining, was initially proposed as a relatively specific means for detection of the footprint of peroxynitrite [29] Recent evidence indicates, however, that certain other reactions can also induce tyrosine nitration: the reaction of nitrite with hypochlorous acid and the reaction of MPO with hydrogen peroxide can lead to the formation of nitrotyrosine [30]. Increased nitrotyrosine staining is thus considered an indication of increased nitrosative stress rather than a specific marker of peroxynitrite.

Poly(ADP-ribose) is synthesized from NAD by PARP and degraded by poly(ADP-ribose) glycohydrolase (PARG). PARP is activated in response to DNA damage as a repair mechanism but also causes NAD and ATP depletion, potentially exacerbating ischemic injury. A principal source of DNA damage is likely to be peroxynitrite formation from superoxide and nitric oxide, mediated by NMDA receptor activation $[31,32]$

We demonstrate here that TP significantly reduced the increase in PARP activity caused by DNBS-induced colitis.

A key event in the inflammatory response is the localized recruitment of various leukocyte subsets. Recruitment of leukocytes is critical to many of the processes studied in oral biology. With the development of new tools such as monoclonal antibody production and transgenic mice, the specific adhesion molecules thought to be important in leukocyte recruitment have been identified and their function examined. These molecules can be divided into three major classes: selectins, members of the immunoglobulin superfamily, and integrins. They mediate interactions between leukocytes and endothelial cells, facilitating the initial process of leukocyte rolling, firm attachment to endothelium, transendothelial migration, diapedesis, and migration along connective tissue.[33]

In the present study, we have confirmed that DNBS administration induced the appearance of P-selectin on the endothelial vascular wall and up-regulated the surface expression of ICAM-1 on 
endothelial cells. Treatment with TP abolished the expression of P-selectin and the up-regulation of ICAM-1 without effecting constitutive levels of ICAM-1 on endothelial cells. These results demonstrate that TP may interrupt the interaction of neutrophils and endothelial cells both at the early rolling phase mediated by P-selectin and at the late firm adhesion phase mediated by ICAM. The absence of an increased expression of the adhesion molecule in the colon tissue of DNBStreated administered TP correlated with the reduction of leukocyte infiltration as assessed by the specific granulocyte enzyme MPO and with the attenuation of the colon tissue damage as evaluated by histological examination.

Taken together, the data presented in the present study demonstrates that TP treatment exerts therapeutic activity on Th1-mediated experimental acute colitis, suggesting that TP could represent a target for therapeutic intervention in autoimmune/inflammatory disorders such as IBD. Moreover, future studies using different animals (mouse/rabbit) or in an acetic acid or DSS colitis models are needed in order to better clarify the possible use of TP for the treatment of IBD patients. 


\section{Acknowledgements}

This work was supported by IRCCS Centro Neurolesi "Bonino-Pulejo", Messina, Italy. The authors thank Giovanni Pergolizzi and Carmelo La Spada for their excellent technical assistance during this study, Mrs. Caterina Cutrona for secretarial assistance and Miss Valentina Malvagni for editorial assistance with the manuscript 


\section{References}

1. Podolsky DK. Inflammatory bowel disease. N Engl J Med 2002;347:417-429.

2. Fiocchi C. Inflammatory bowel disease pathogenesis: therapeutic implications. Chin J Dig Dis 2005;6:6-9.

3. Jump RL, Levine AD. Mechanisms of natural tolerance in the intestine: implications for inflammatory bowel disease. Inflamm Bowel Dis 2004;10:462-478.

4. Stallmach A, Strober W, MacDonald TT, Lochs H, Zeitz M. Induction and modulation of gastrointestinal inflammation. Immunol Today 1998;19:438-441.

5. Podolsky DK. Nutrition and Crohn's disease. J Gastroenterol 2000;35 Suppl 12:18.

6. Babbs CF. Oxygen radicals in ulcerative colitis. Free Radic Biol Med 1992;13:169-181.

7. Rezaie A, Parker RD, Abdollahi M. Oxidative stress and pathogenesis of inflammatory bowel disease: an epiphenomenon or the cause? Dig Dis Sci 2007;52:2015-2021.

8. Keshavarzian A, Morgan G, Sedghi S, Gordon JH, Doria M. Role of reactive oxygen metabolites in experimental colitis. Gut 1990;31:786-790.

9. Middleton E, Jr. Some biological properties of plant flavonoids. Ann Allergy 1988;61:5357.

10. Denisov AI, Afanas'ev VI. [Biological bases of posthodiplostomatosis control in pond fish]. Veterinariia 1973;7:63-65.

11. Kurkin VA. Phenylpropanoids from medicinal plants: distribution, classification, structural analysis, and biological activity. Chem Nat Compd 2003;39: :123-153.

12. Lee JY, Woo ER, Kang KW. Inhibition of lipopolysaccharide-inducible nitric oxide synthase expression by acteoside through blocking of AP-1 activation. J Ethnopharmacol 2005;97:561-566.

13. Tognolini M, Barocelli E, Ballabeni V, Bruni R, Bianchi A, Chiavarini M, Impicciatore M, et al. Comparative screening of plant essential oils: phenylpropanoid moiety as basic core for antiplatelet activity. Life Sci 2006;78:1419-1432. 
14. Hsu S. Green tea and the skin. J Am Acad Dermatol 2005;52:1049-1059.

15. Kris-Etherton PM, Hecker KD, Bonanome A, Coval SM, Binkoski AE, Hilpert KF, et al. Bioactive compounds in foods: their role in the prevention of cardiovascular disease and cancer. Am J Med 2002;113 Suppl 9B:71S-88S.

16. Korkina L, Mikhal'chik E, Suprun M, Pastore S., R. DT. Molecular mechanisms underlying wound healing and anti-inflammatory properties of naturally occurring biotechnologically produced phenylpropanoid glycosides. Cell and Mol Biology 2006;53:78-83.

17. Mullane KM, Kraemer R, Smith B. Myeloperoxidase activity as a quantitative assessment of neutrophil infiltration into ischemic myocardium. Journal of pharmacological methods $1985 ; 14: 157-167$.

18. Riccardi L, Mazzon E, Bruscoli S, Esposito E, Crisafulli C, Di Paola R, Caminiti R, Riccardi C, Cuzzocrea S. PPAR-alpha MODULATES THE ANTI-INFLAMMATORY EFFECT OF GLUCOCORTICOIDS IN A MODEL OF INFLAMMATORY BOWEL DISEASE IN MICE. Shock. 2008 Jul 24.

19. Bouma G, Strober W. The immunological and genetic basis of inflammatory bowel disease. Nat Rev Immunol 2003;3:521-33.

20. Strober W, Fuss I, Mannon P. The fundamental basis of inflammatory bowel disease. J Clin Invest 2007;117:514-21.

21. Neurath MF, Finotto S, Fuss I, et al. Regulation of T-cell apoptosis in inflammatory bowel disease: to die or not to die, that is the mucosal question. Trends Immunol 2001;22:21-6.

22. MacDonald TT, Bajaj-Elliott M, Pender SL. T cells orchestrate intestinal mucosal shape and integrity. Immunol Today 1999;20:505-10.

23. Shapiro H, Singer P, Halpern Z, Bruck R. Polyphenols in the treatment of inflammatory bowel disease and acute pancreatitis. Gut 2007;56:426-435. 
24. Lu Y, Wahl LM. Production of matrix metalloproteinase-9 by activated human monocytes involves a phosphatidylinositol-3 kinase/Akt/IKKalpha/NF-kappaB pathway. J Leukoc Biol $2005 ; 78: 259-265$.

25. Medina C, Radomski MW. Role of matrix metalloproteinases in intestinal inflammation. J Pharmacol Exp Ther 2006;318:933-938.

26. Ji LL, Gomez-Cabrera MC, Vina J. Role of nuclear factor kappaB and mitogen-activated protein kinase signaling in exercise-induced antioxidant enzyme adaptation. Appl Physiol Nutr Metab 2007;32:930-935.

27. Cross RK, Wilson KT. Nitric oxide in inflammatory bowel disease. Inflamm Bowel Dis 2003;9:179-189.

28. Therond P. [Oxidative stress and damages to biomolecules (lipids, proteins, DNA)]. Ann Pharm Fr 2006;64:383-389.

29. Beckman JS. Oxidative damage and tyrosine nitration from peroxynitrite. Chemical research in toxicology 1996;9:836-844.

30. Eiserich JP, Hristova M, Cross CE, Jones AD, Freeman BA, Halliwell B,_et al. Formation of nitric oxide-derived inflammatory oxidants by myeloperoxidase in neutrophils. Nature 1998;391:393-397.

31. Giovannelli L, Cozzi A, Guarnieri I, Dolara P, Moroni F. Comet assay as a novel approach for studying DNA damage in focal cerebral ischemia: differential effects of NMDA receptor antagonists and poly(ADP-ribose) polymerase inhibitors. J Cereb Blood Flow Metab 2002;22:697-704.

32. Mandir AS, Poitras MF, Berliner AR, et al. NMDA but not non-NMDA excitotoxicity is mediated by Poly(ADP-ribose) polymerase. J Neurosci 2000;20:8005-8011.

33. Penberthy TW, Jiang Y, Graves DT. Leukocyte adhesion molecules. Crit Rev Oral Biol Med 1997;8:380-388. 


\section{Figure legends}

Figure 1: chemical structure of teupolioside (a). Chromatogram of the Ajuga reptans extract measured at $330 \mathrm{~nm}$. TP is the peak with retention time 4.839 minutes (b).

\section{Figure 2. Effect of TP treatment on colon injury and body weight changes after DNBS} intracolonic administration. Colon tissues from sham-treated rats (a), colon tissues from DNBStreated rats at 4 days post DNBS administration (b) and the colon tissues collected from DNBStreated rats which have received TP at $2 \mathrm{mg} / \mathrm{kg}(\mathbf{c})$ or at $0.2 \mathrm{mg} / \mathrm{kg}$ (d) treatment. No histological alteration was observed in the colon section from sham-treated rats (e). Mucosal injury was produced after DNBS administration characterized by absence of epithelium and a massive mucosal and submucosal infiltration of inflammatory cells (f). Treatment with TP at $2 \mathrm{mg} / \mathrm{kg}(\mathbf{g})$ corrected in a dose dependent manner the disturbances in morphology associated with DNBS administration. The macroscopic damage score and The histological score (h,i) was made by two independent observers. Figure is representative of all the animals in each group. Treatment with TP at $2 \mathrm{mg} / \mathrm{kg}$ or at $0.2 \mathrm{mg} / \mathrm{kg}$ significantly reduced in a dose dependent manner the increase in body weight loss (I). Data are means \pm SEM of 10 rats for each group. $* P<0.01$ vs. SHAM; ${ }^{\circ} P<0.01 v s$. DNBS.

Figure 3. Effect of TP treatment on colon levels and Immunohistochemical localization of TNF- $\alpha$ and IL-1 $\beta$.

immunohistochemical analysis for TNF- $\alpha$ and IL-1 $\beta$ (a,d) show positive staining localized in the inflammatory cells in the injured area from DNBS-treated animals. The intensity of the positive staining for TNF- $\alpha$ and IL-1 $\beta$ (b,e) was markedly reduced in tissue section obtained from DNBStreated animals which have been treated with TP $(2 \mathrm{mg} / \mathrm{kg})$. Densitometry analysis of immunohistochemistry photographs ( $n=5$ photos from each sample collected from all rats in each experimental group) for TNF- $\alpha$ and IL-1 $\beta$ (c,f) from colon tissues was assessed. The assay was carried out by using Optilab Graftek software on a Macintosh personal computer (CPU G3-266). 
Data are expressed as \% of total tissue area. Moreover treatment with TP at $2 \mathrm{mg} / \mathrm{kg}$ or at $0.2 \mathrm{mg} / \mathrm{kg}$ significantly reduced in a dose dependent manner the increase of cytokine production (g,h) in the colon tissue after DNBS administration. This figure is representative of at least 3 experiments performed on different experimental days. ${ }^{*} P<0.01$ vs. SHAM; ${ }^{\circ} P<0.01$ vs. DNBS.

\section{Figure 4. Effects of TP treatment on Immunohistochemical localization of ICAM-I, P-selectin} and on polymorphonuclear leukocyte infiltration in the colon. Immunohistochemical analysis for ICAM-1 and P-selectin (a,d) show positive staining mainly localized on endothelial cells and in the inflammatory cells in the injured area from DNBS-treated rats. The intensity of the positive staining for ICAM-1 and P-selectin (b,e) was markedly reduced in tissue section obtained from DNBS-treated rats which have been treated with TP $(2 \mathrm{mg} / \mathrm{kg})$. Densitometry analysis of immunocytochemistry photographs ( $\mathrm{n}=5$ photos from each sample collected from all rats in each experimental group) for ICAM-1 and P-selectin (c,f) from colon tissues was assessed. The assay was carried out by using Optilab Graftek software on a Macintosh personal computer (CPU G3-266). Data are expressed as \% of total tissue area. Myeloperoxidase (MPO) activity (g) was significantly increased in DNBS-treated rats in comparison to sham-treated rats. Treatment with TP at $2 \mathrm{mg} / \mathrm{kg}$ or at $0.2 \mathrm{mg} / \mathrm{kg}$ significantly reduced in a dose dependent manner the colon MPO activity. This figure is representative of at least 3 experiments performed on different experimental days. ${ }^{*} P<0.01 v s$. SHAM; ${ }^{\circ} P<0.01$ vs. DNBS.

\section{Figure 5. Effects of TP treatment on Immunohistochemical localization of iNOS in the colon.}

No positive staining for iNOS was observed in the colon tissues from sham-treated rats (a). Immunohistochemical analysis for $\operatorname{iNOS}$ (b) show positive staining mainly localized in the inflammatory cells in the injured area from DNBS-treated rats. The intensity of the positive staining for iNOS (c) was markedly reduced in tissue section obtained from DNBS-treated rats which have been treated with TP $(2 \mathrm{mg} / \mathrm{kg})$. Densitometry analysis of immunocytochemistry photographs $(\mathrm{n}=5$ 
photos from each sample collected from all rats in each experimental group) for iNOS (d) from colon tissues was assessed. The assay was carried out by using Optilab Graftek software on a Macintosh personal computer (CPU G3-266). Data are expressed as \% of total tissue area. This figure is representative of at least 3 experiments performed on different experimental days. ${ }^{*} P<0.01$ vs. SHAM; ${ }^{\circ} P<0.01$ vs. DNBS.

Figure 6. Effects of TP treatment on nitrotyrosine and PAR formation and lipid peroxidation. Sections obtained from DNBS-treated rats demonstrate positive staining for nitrotyrosine and PAR (a,d) mainly localized in inflammatory cells. TP $(2 \mathrm{mg} / \mathrm{kg})$ treatment reduced the degree of positive staining for nitrotyrosine and PAR (b,e) in the colon tissues. Densitometry analysis of immunocytochemistry photographs $(\mathrm{n}=5$ photos from each sample collected from all rats in each experimental group) for nitrotyrosine and PAR (c,f) from colon tissues was assessed. The assay was carried out by using Optilab Graftek software on a Macintosh personal computer (CPU G3-266). Data are expressed as \% of total tissue area. In addition, a significant increase in thiobarbituric acid-reactant substances (g) were observed in the colon tissues collected at 4 days after DNBS administration when compared with sham-treated rats. Thiobarbituric acid-reactant substances were significantly attenuated in a dose dependent manner by TP treatment (g). Figures are representative of at least 3 experiments performed on different experimental days. Data are means \pm s.e. means of 10 rats for each group. ${ }^{*} P<0.01 v s$. SHAM; ${ }^{\circ} P<0.01 v s$. DNBS.

Figure 7. Effects of TP treatment on IKB- $\alpha$ degradation, phosphorylation of Ser536 on the NF- $\kappa$ B subunit p65, total NF- $\kappa$ B p65

By Western Blot analysis, a basal level of $I \kappa B-\alpha$ was detected in the colon tissues from shamtreated animals, whereas I $\kappa \mathrm{B}-\alpha$ levels were substantially reduced in DNBS-treated rats. TP (2 $\mathrm{mg} / \mathrm{kg}$ ) treatment prevented the DNBS-induced $\mathrm{I} \kappa \mathrm{B}-\alpha$ degradation (a). In addition, DNBS administration caused a significant increase in the phosphorylation of Ser536 at 4 days (b) and in 
nuclear NF-kB p65 (c) compared to the sham-treated rats. TP $(2 \mathrm{mg} / \mathrm{kg})$ treatment significantly reduced the phosphorylation of p65 on Ser536 (b) and NF-kB p65 levels as shown in c. A representative blot of lysates obtained from three/four animals per group is shown, and densitometric analysis of all animals is reported ( $\mathrm{n}=5$ rats from each group).

The relative expression of the protein bands from three separated experiments was standardized for densitometric analysis to $\beta$-actin or lamin levels, and reported in a1, b1, c1. ${ }^{*} P<0.01$ vs. SHAM; ${ }^{\circ} P<0.01 v s$. DNBS.

Figure 8. Effects of TP treatment on MMP-2 and MMP-9 activity. by zymogram and its densitometric analysis

Pro-MMP-2 and pro-MMP-9 activity was observed in colon tissues extracts prepared from shamtreated rats (panels a,b,d). In contrast to sham-treated rats, colon tissues extracts from DNBS-treated rats showed an induction of pro-MMP-2 (panels a and b) and pro-MMP-9 (panels a and d). Active form of MMP-2 and MMP-9 was also evidenced (panel a,c and e). TP ( $2 \mathrm{mg} / \mathrm{kg})$ treatment reduced the degree of activation of pro-MMP-2 and pro-MMP-9 activity as well as active form of MMP-2 and MMP-9 (panels a,c,e). This figure is representative of at least 3 experiments performed on different experimental days. ${ }^{*} P<0.01$ vs. SHAM; ${ }^{\circ} P<0.01 v s$. DNBS.

\section{Figure 9- Effects of TP treatment on MMP-2 and MMP-9 expression by Western blot analysis.}

A basal level of pro-MMP-2 expression was detected in tissues from control animals, as shown by band migrating at $\sim 70 \mathrm{kDa}$ (panel A, see densitometry a1). Upregulation of pro-MMP-2 was observed in DNBS-treated rats when compared with controls. TP $(2 \mathrm{mg} / \mathrm{kg})$ treatment significantly prevented DNBS-induced MMP-2 expression (panel A, see densitometry analysis A1). Similarly, a very low level of pro-MMP-9 was detected in tissues from control group, as shown by the immunoreactive band migrating at $\sim 92 \mathrm{kDa}$ (panel $\mathrm{b}$, see densitometry analysis b1). A significant 
upregulation of pro-MMP-9 was observed in the colon tissues from DNBS-treated animals when compared with controls. TB $(2 \mathrm{mg} / \mathrm{kg})$ treatment also significantly prevented DNBS-induced proMMP-9 expression (panel B, see densitometry analysis B1). Moreover, activeMMP-2 form was significantly expressed in DNBS-treated rats, while TP $(2 \mathrm{mg} / \mathrm{kg})$ treatment significantly prevented DNBS-induced active MMP-2 expression (panel A,, see densitometry a1)

A representative blot of lysates obtained from three/four animals per group is shown, and densitometric analysis of all animals is reported ( $\mathrm{n}=5$ rats from each group).

The relative expression of the protein bands from three separated experiments, performed on different experimental days, was standardized for densitometric analysis to $\beta$-actin levels,. ${ }^{*} p<0.01$ vs. Sham. ${ }^{\circ} p<0.01$ vs $D N B S+$ vehicle 
b

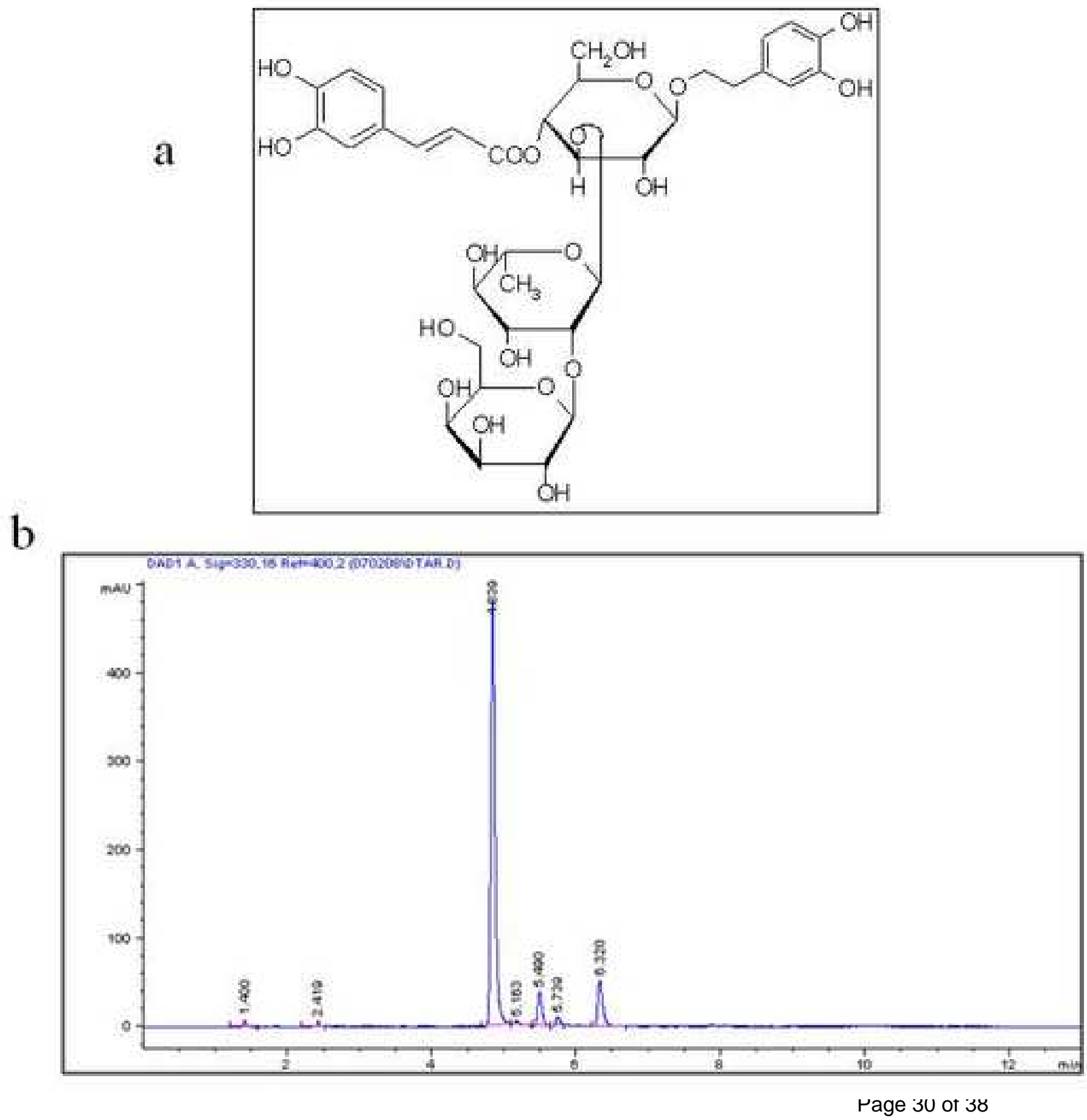

Figure 1 

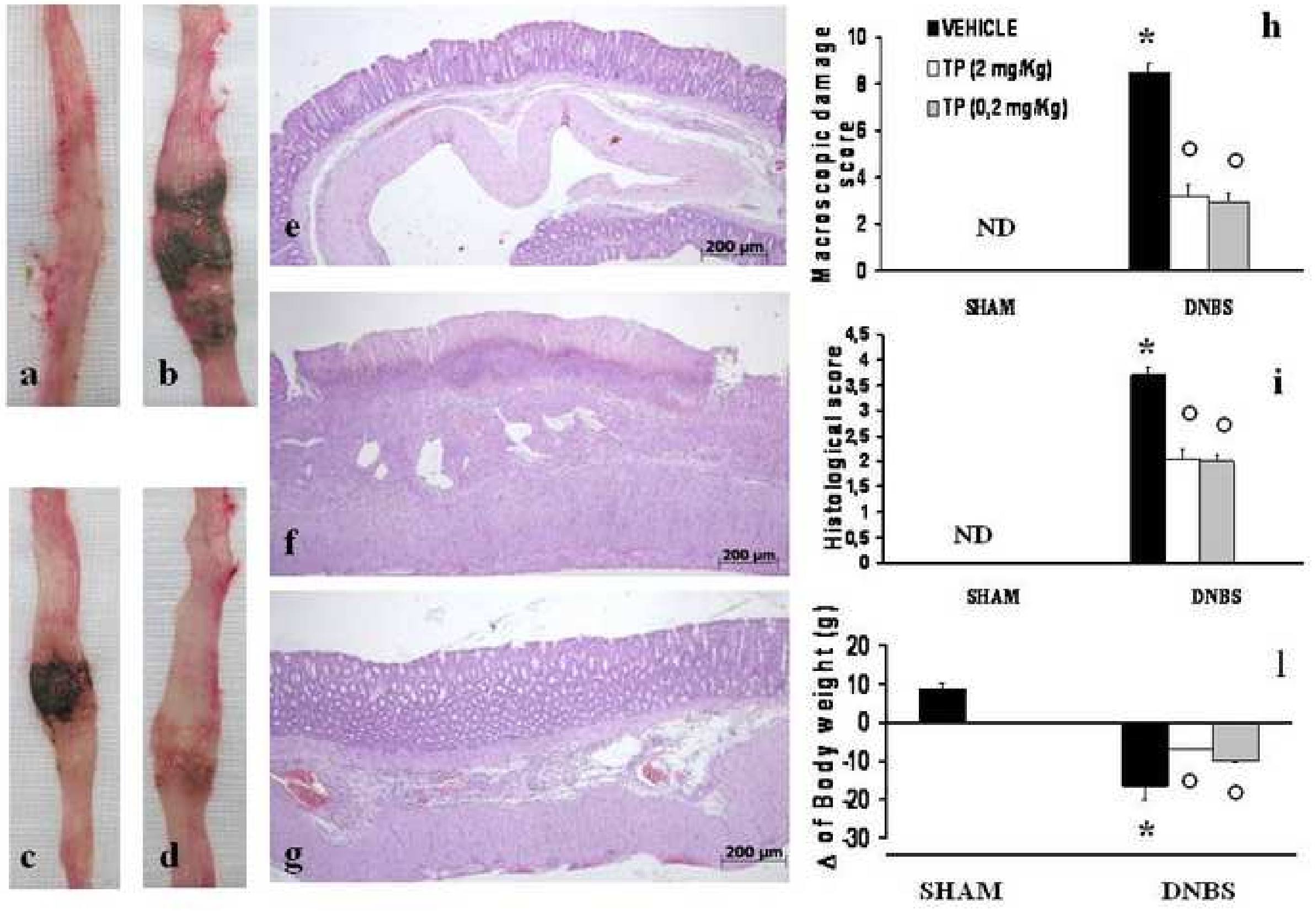

Figure 2 

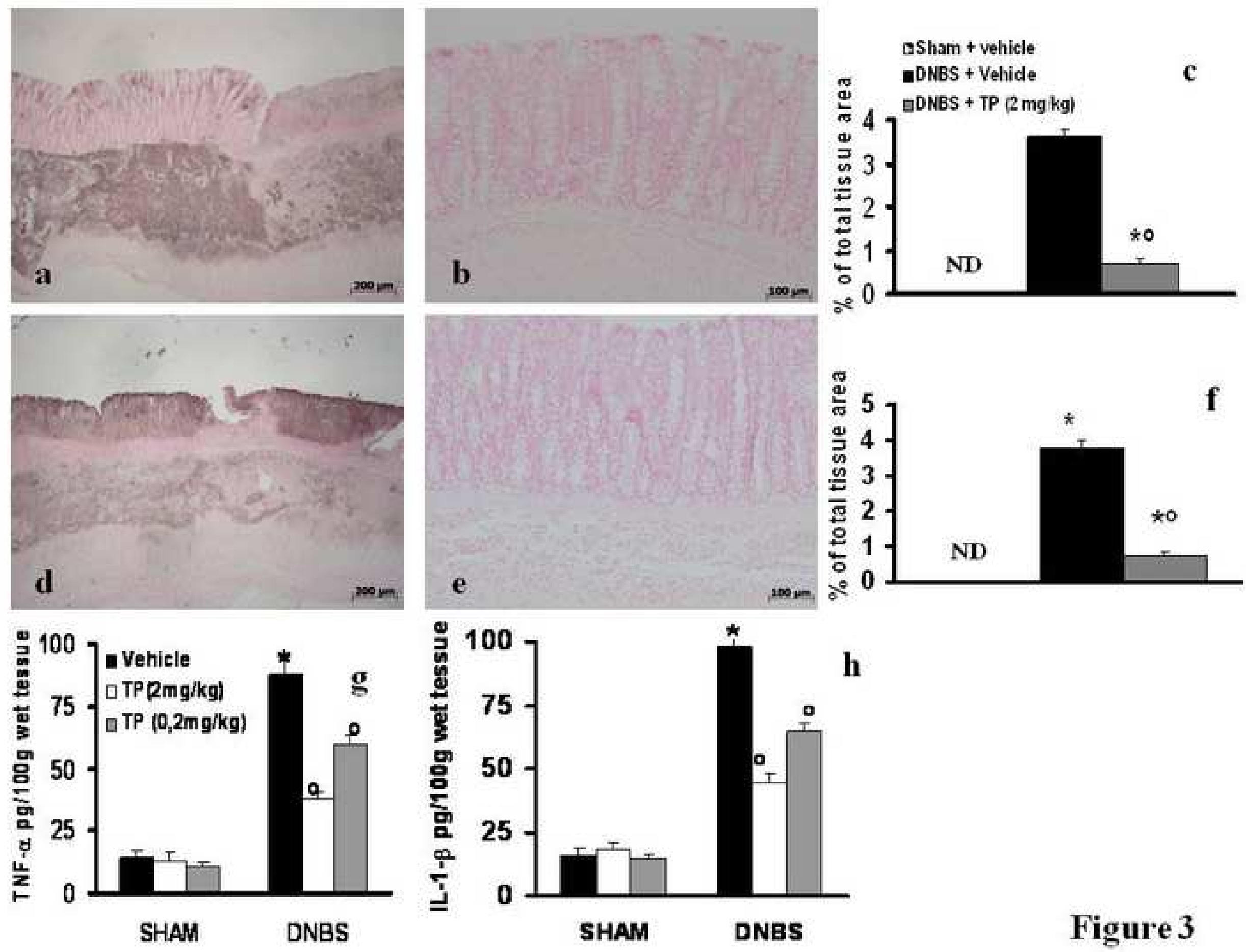


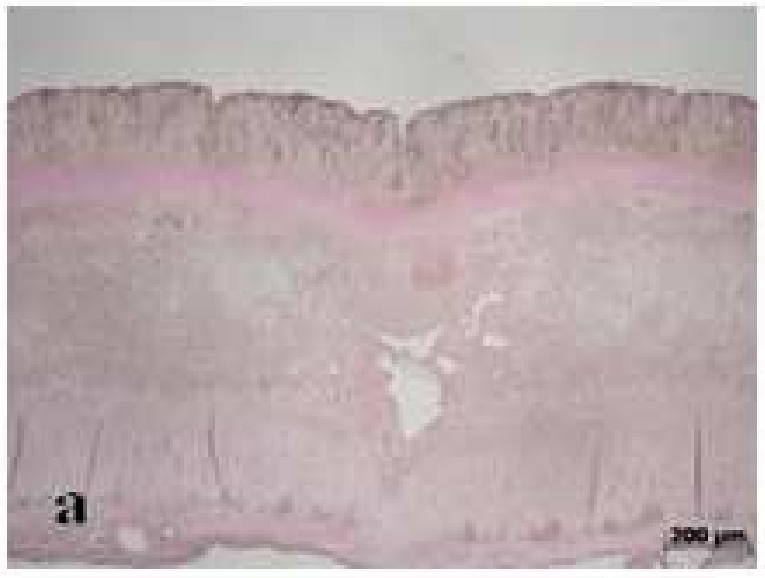

b

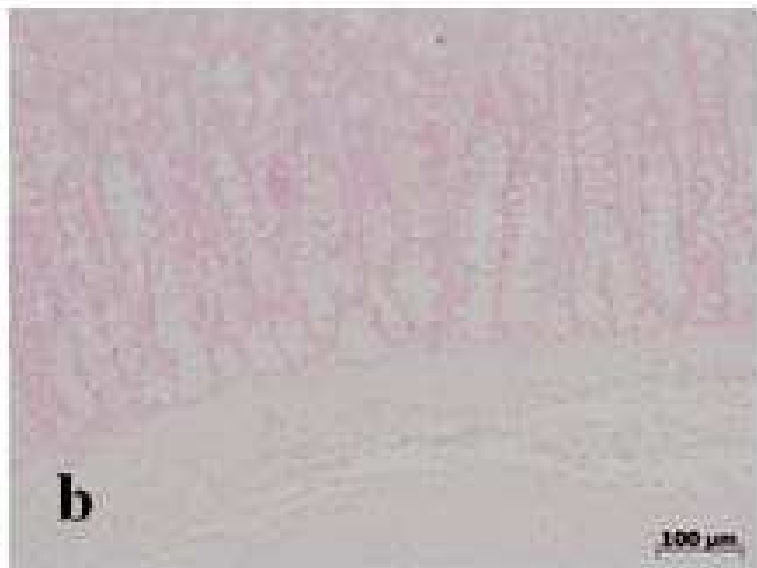

$100 \mathrm{pm}$

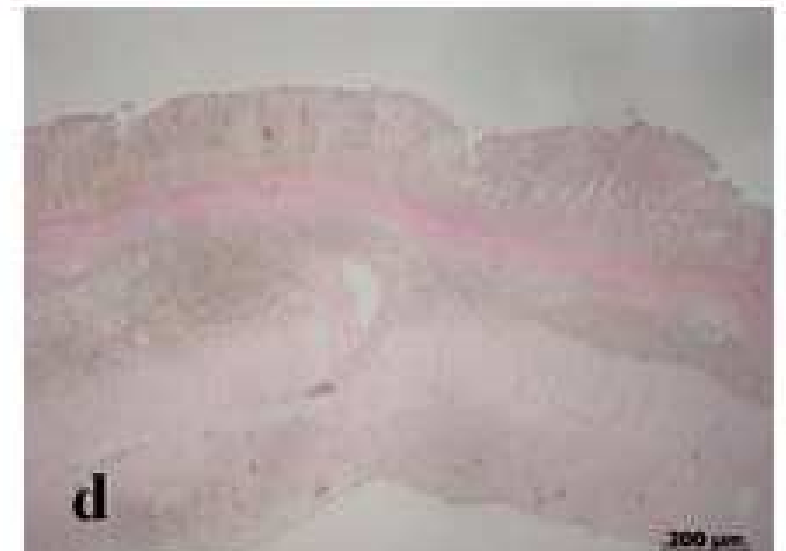

$300 \mathrm{pm}$
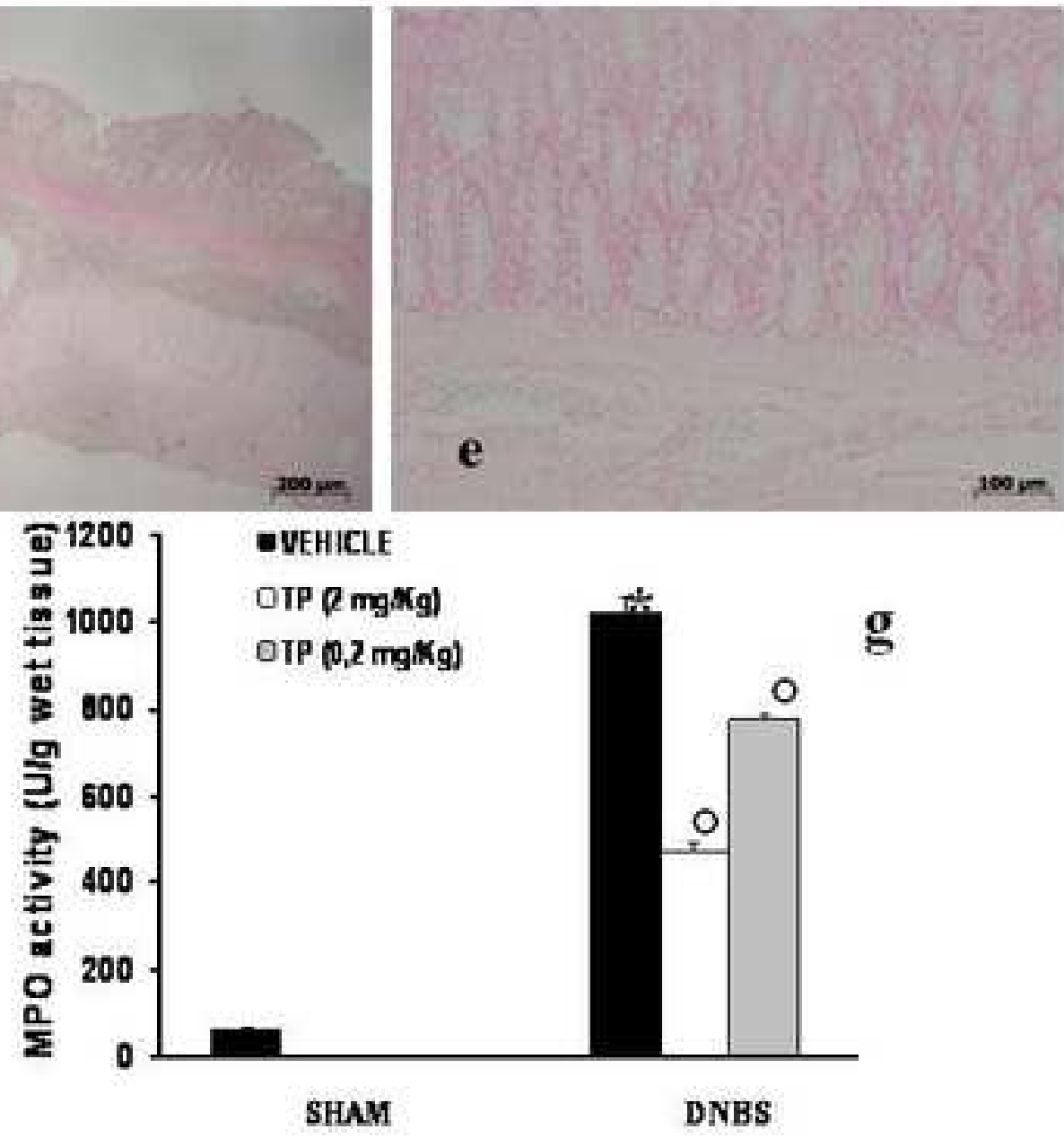

Eham + vehicle

-DNBS + Vehicle
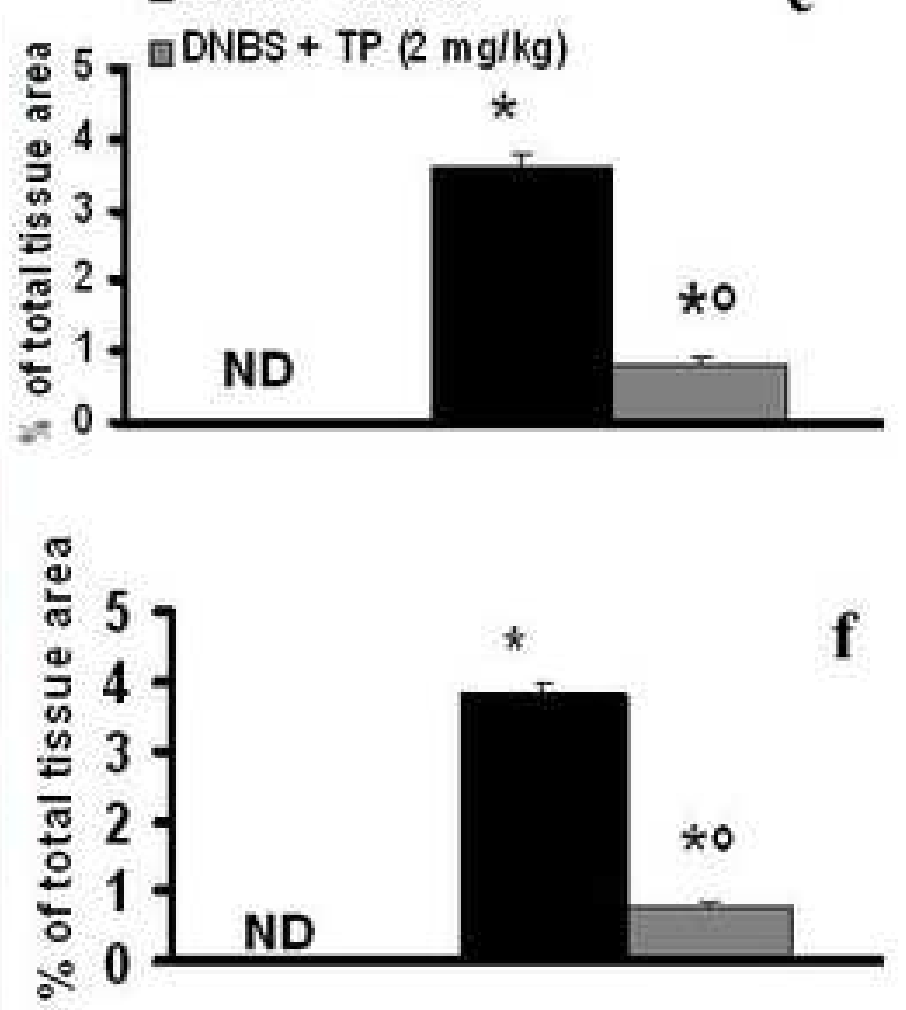
a

$100 \mathrm{\mu m}$

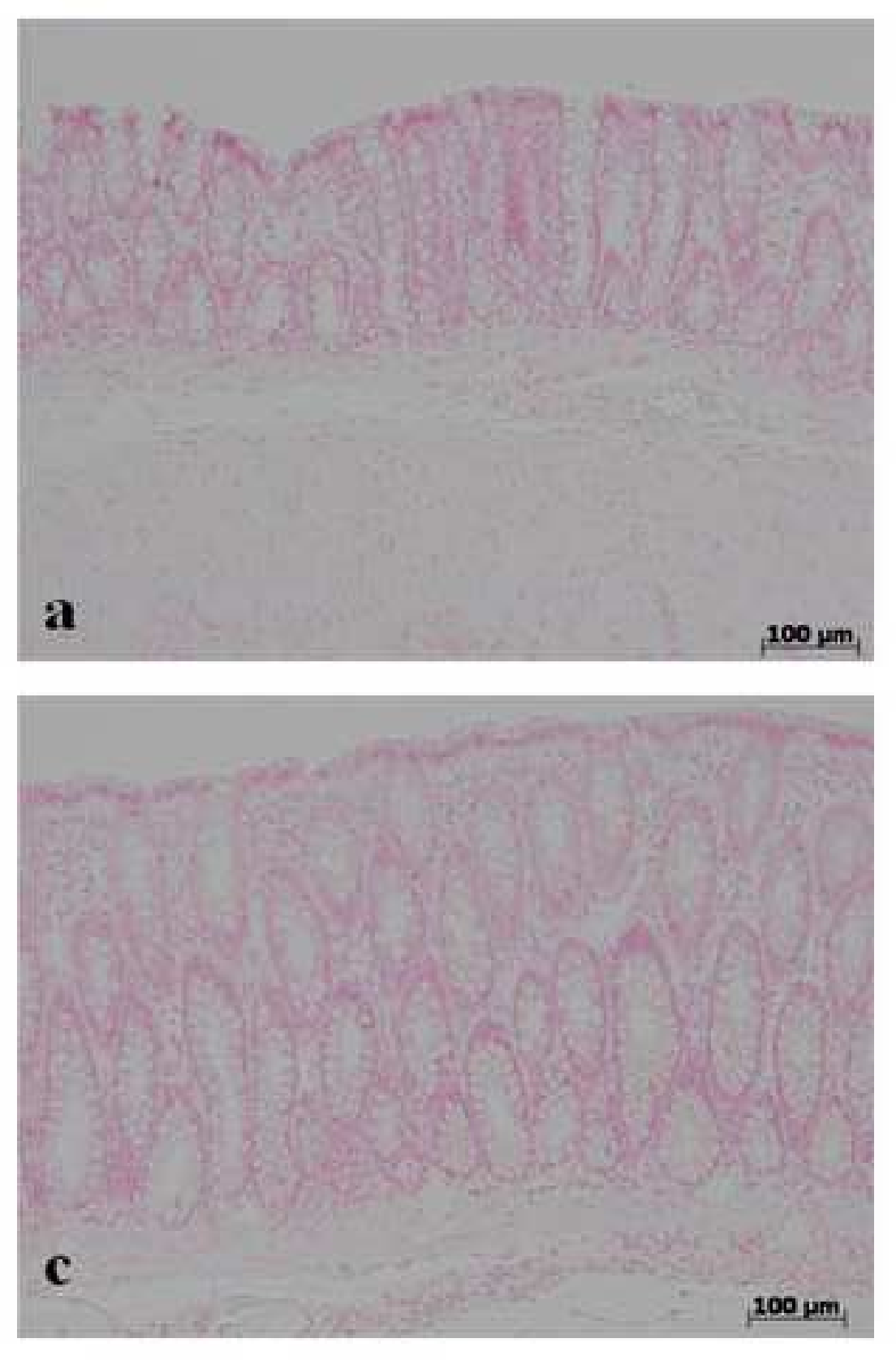

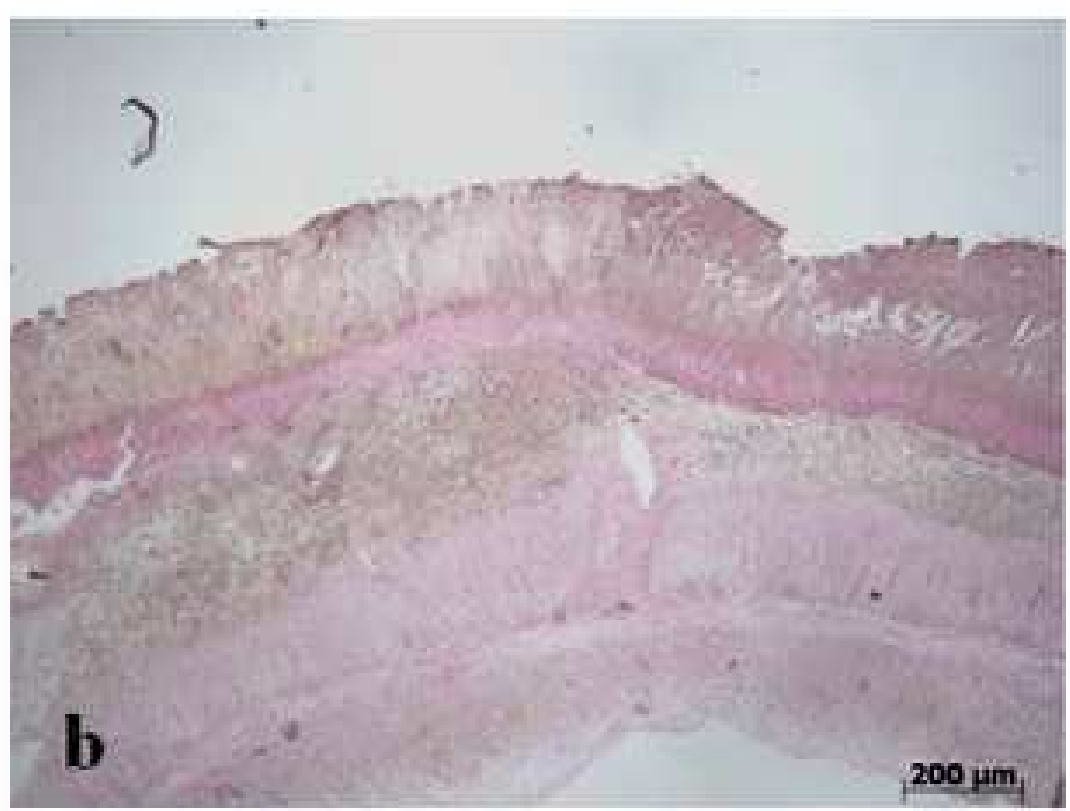

ESham + vehicle

-DNBS + Vehicle

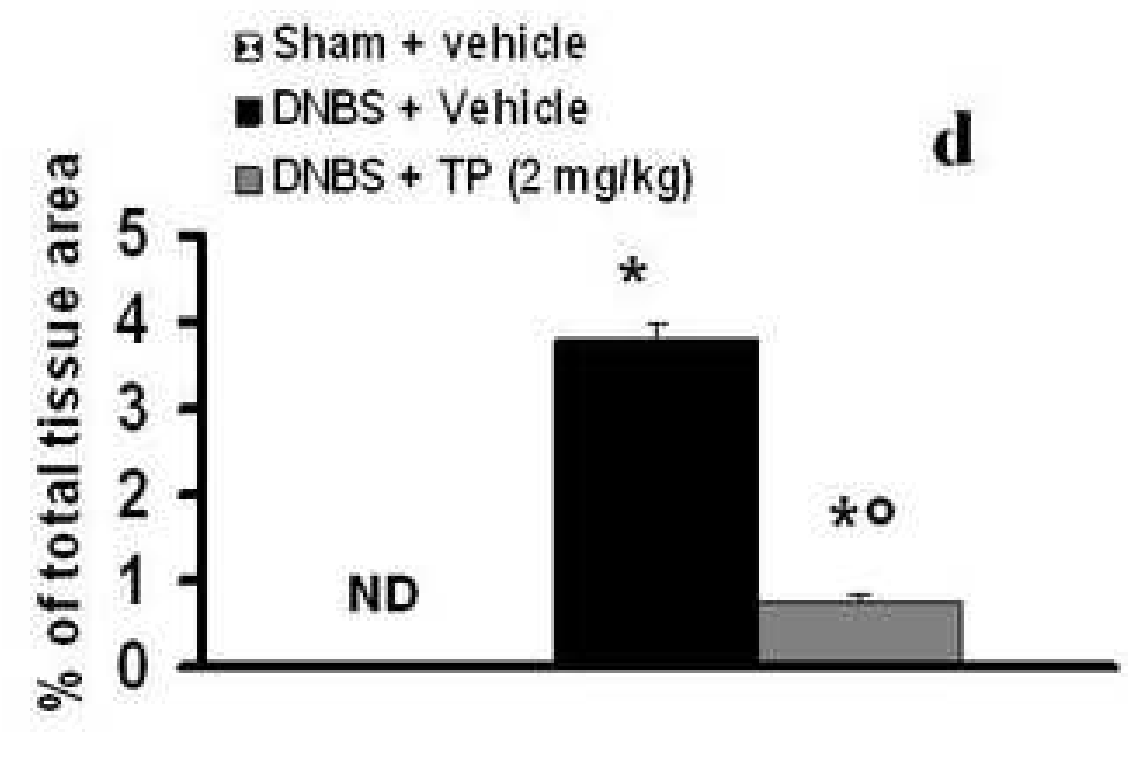

Figure 5

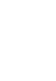



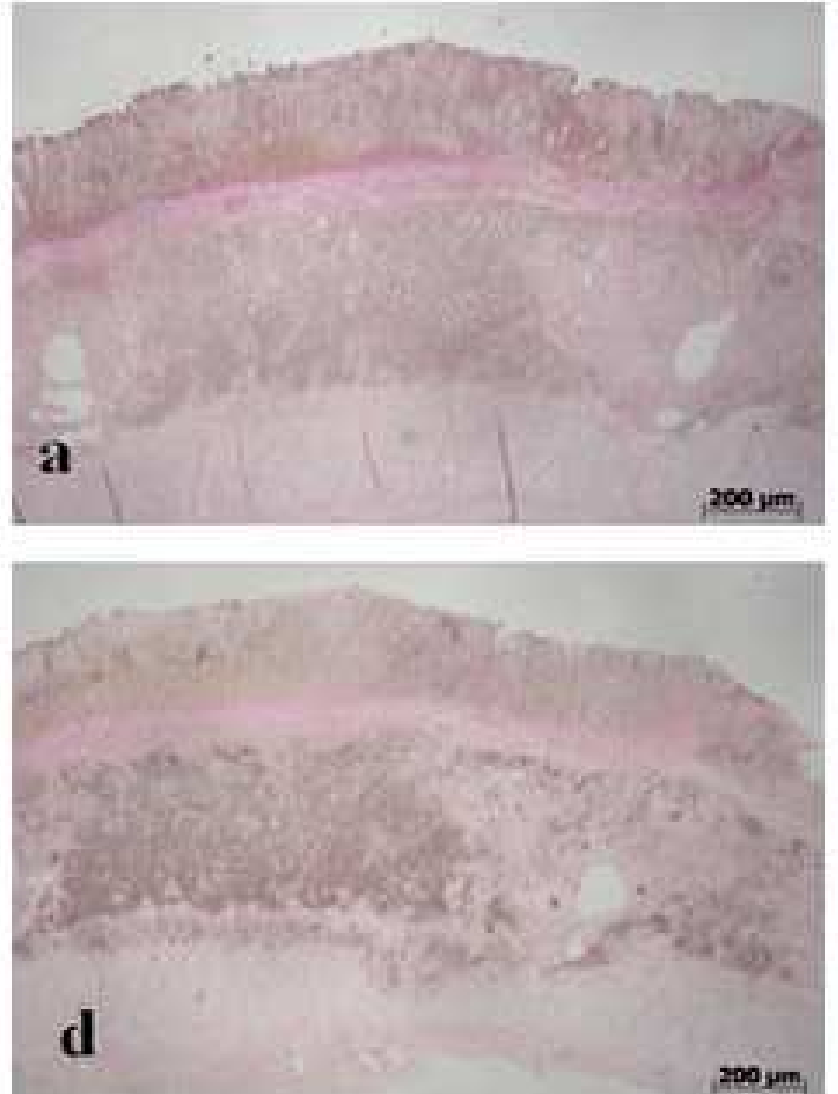

$200 \mathrm{~mm}$
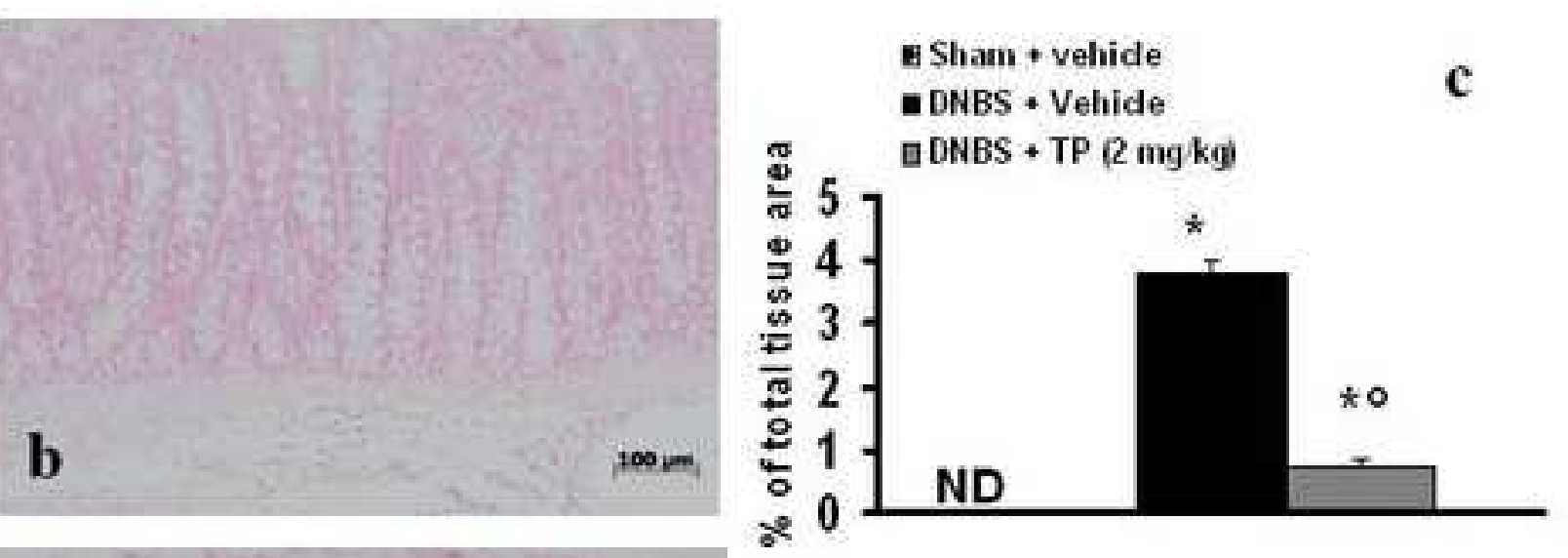

e $100 \mathrm{rm}$
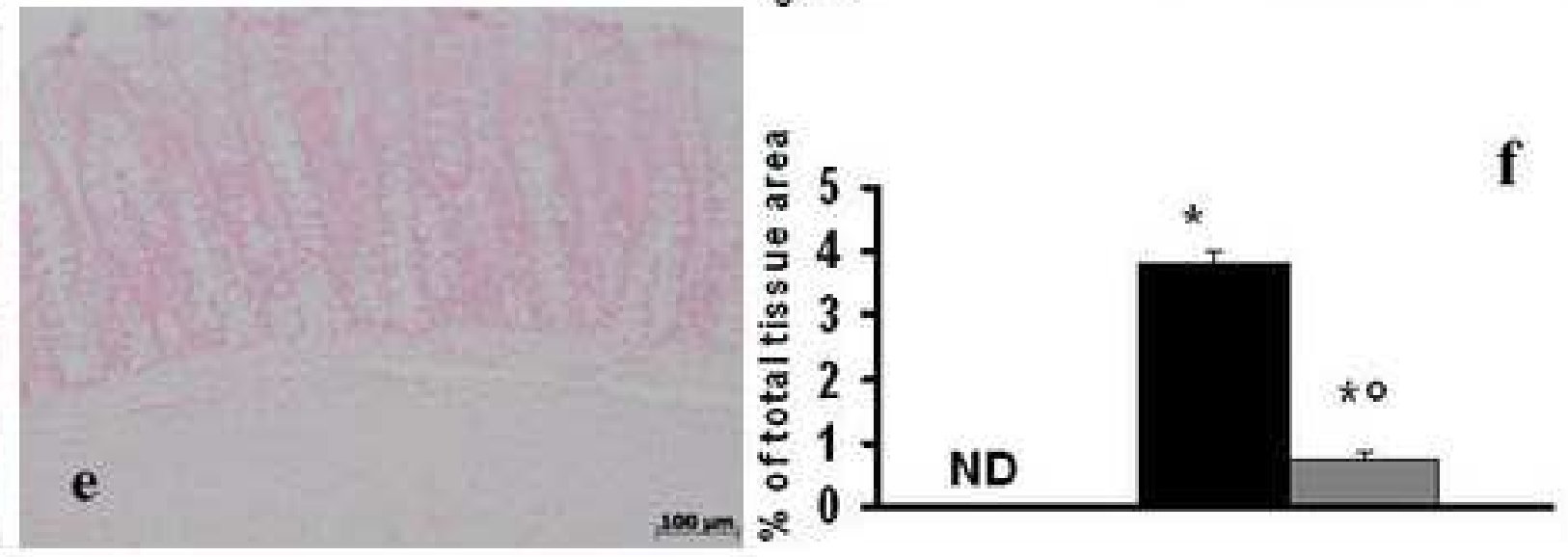

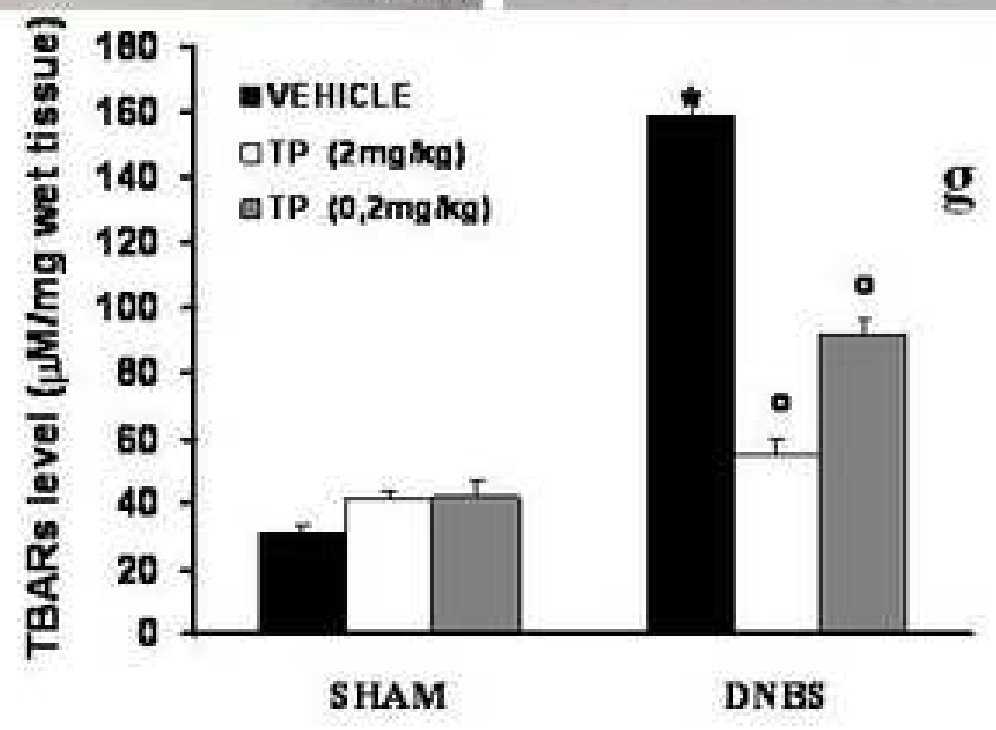

Figure 6 


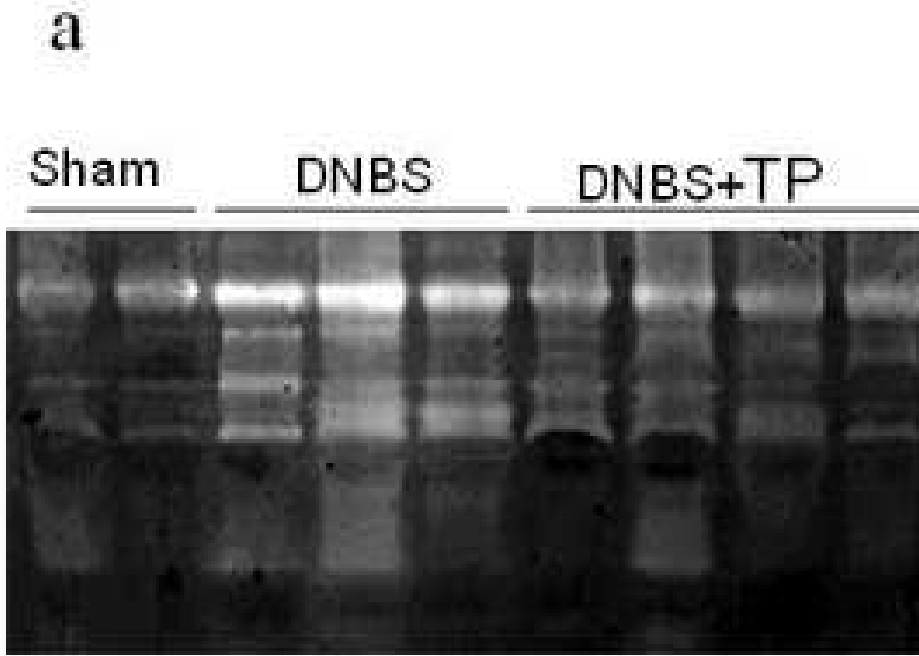

c d

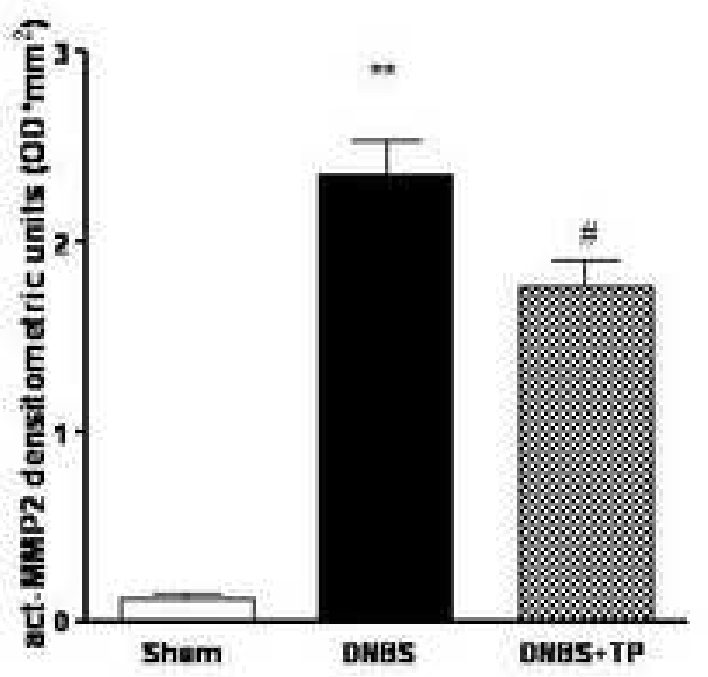

b

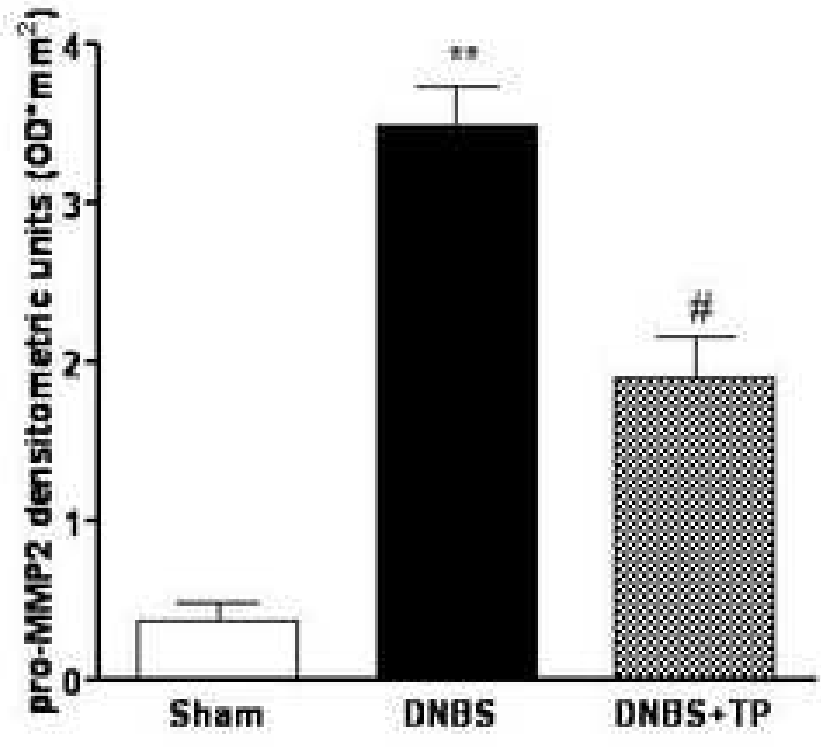

e

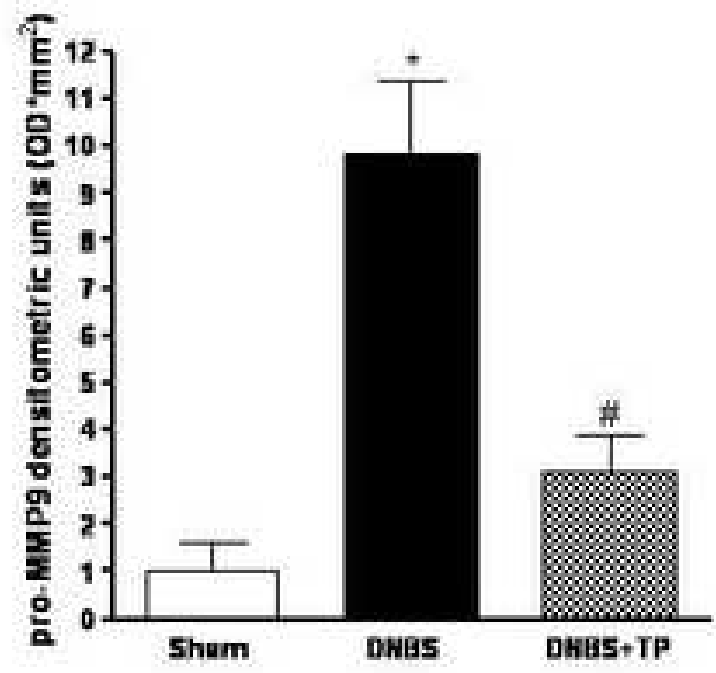

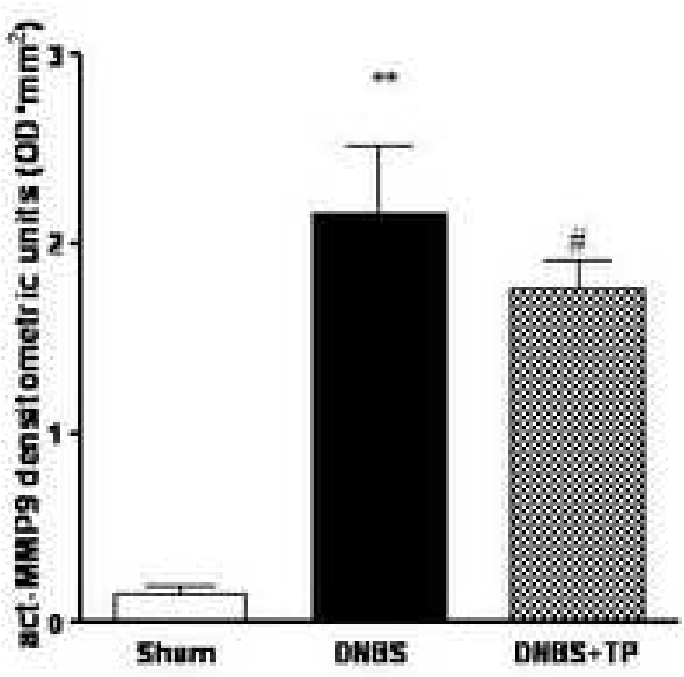

Figure 8 
a

b

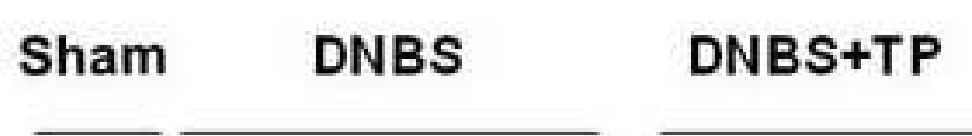

Sham DNBS DNBS+TP

\section{MMP-2}

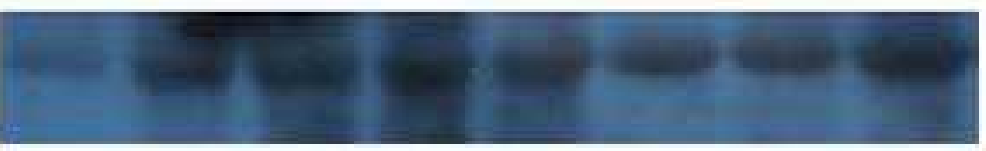

\section{MMP-9}

$\beta$-actin

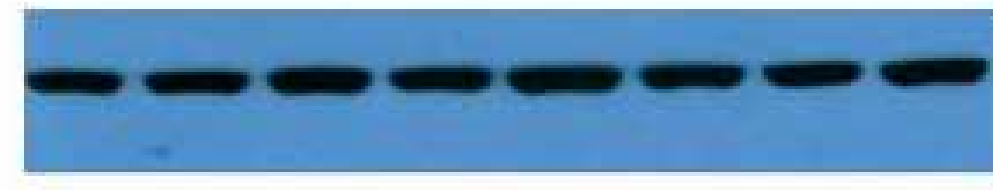

p-actin

a1

$72 \mathrm{kDa}$

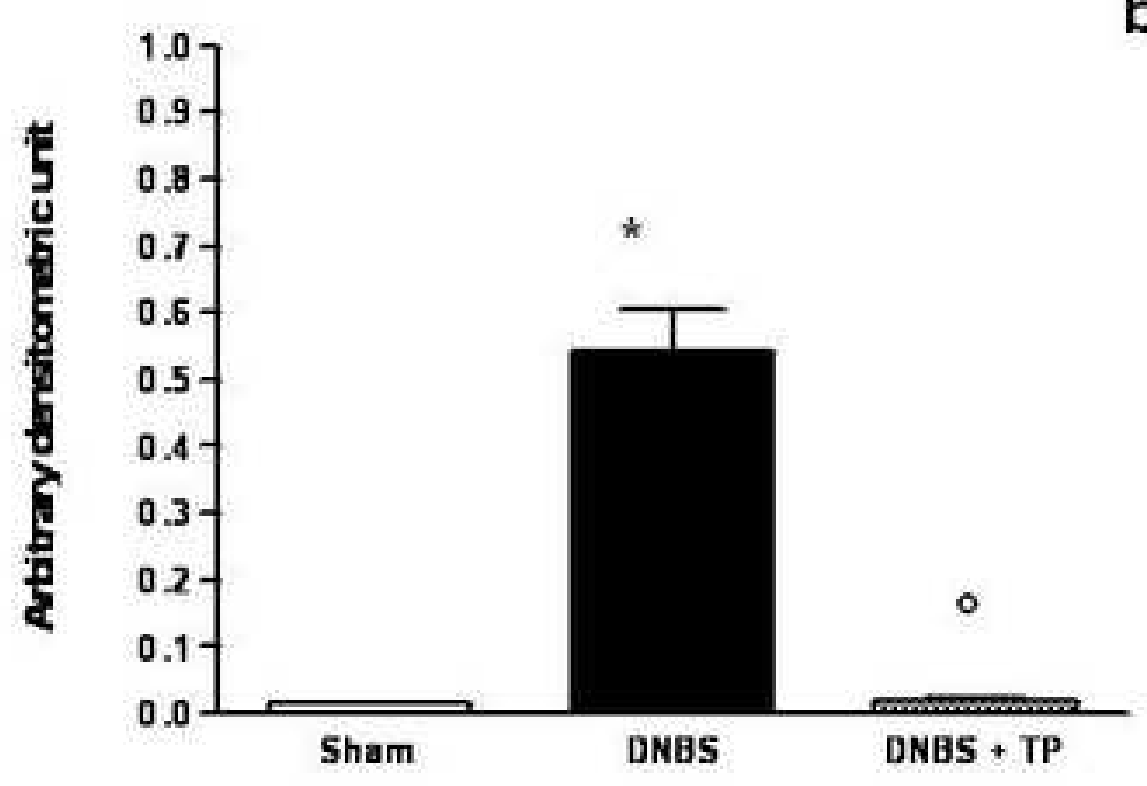

b1

$95 \mathrm{kDa}$

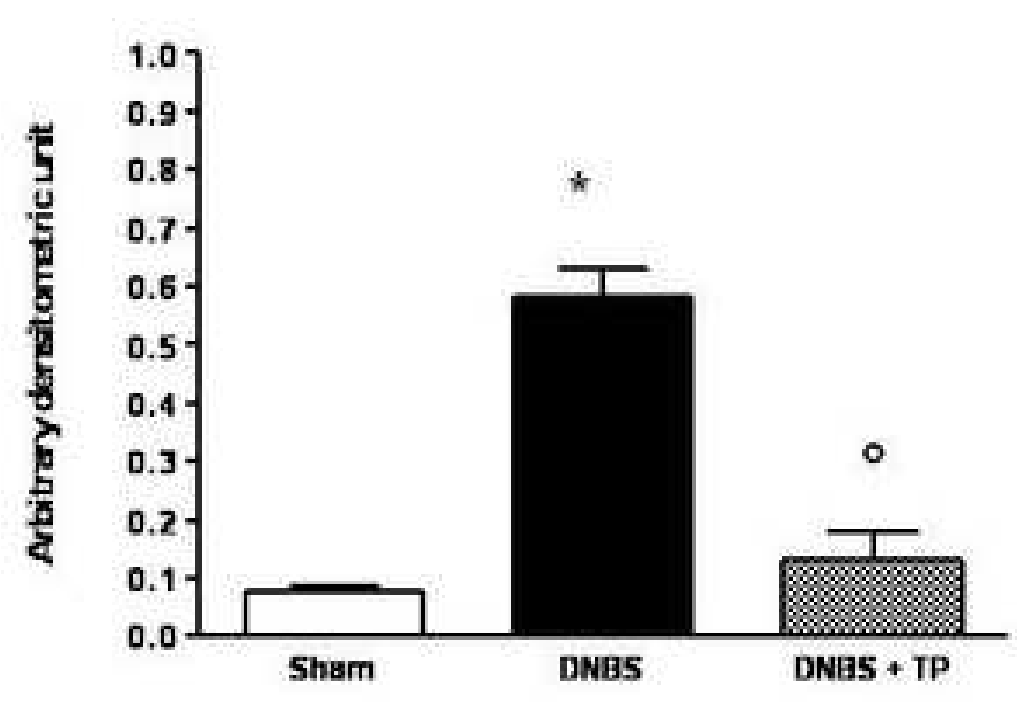

Figure 9

rage зъ от зъ 